\title{
DRUG DEPENDENCE: AN ANALYSIS
}

\author{
W. G. DEWHURST*
}

Dr. Dewhurst favours the establishment of scientific biological criteria to assess the effect of drugs on man and on society and to aid in the reform of contemporary drug legislation. He contends that current tripartite legislation develops three approaches to a problem which the medical profession views as singular. Thus the legislation leads to legal and social paradox. The author proceeds to view the extent of the modern drug problem through available data and suggests that the recent upsurge in drug use is largely attributable to the effective marketing procedures of illicit drug manufacturers. These marketing techniques cater to the human longing for euphoria, and the desire to repeat the euphoria, artificially produced by drugs, may lead to increased use and produce delirium which seriously reduces the users social productivity and life-expectancy. The author concludes that bans placed on drugs have been largely ineffective in controlling distribution and use. The result is a situation, produced by general human needs and illicit marketing procedures, over which society has no control. The solution proposed is to regain control by allowing certain drugs to be cheaply distributed under the control of the medical profession and to legalize other drugs through the passage of legislation similar to provincial liquor legislation.

\section{INTRODUCTION}

\section{PART I-ATTITUDES}

Nowadays it is possible to discuss the pros and cons of alcohol fairly calmly. At least it is recognized that there are two sides to the coin as Sir Winston Churchill's appraisal indicates, "I have taken more from alcohol than it has taken from me." Unfortunately, the topic of drug addiction often generates more emotion than the drugs themselves and reasoned assessment is hard to come by. The harangues (they cannot be called debates) give rise to much heat but little light; as in other areas where facts are few, dispassionate judgment is overshadowed by opinions held with passionate conviction. We must do better than this and the following analysis aims at elucidation rather than incineration.

\section{STANDPOINT OF AUTHOR}

Drug dependency has many aspects, moral, theological, social, cultural, legal, pharmacological, psychological, psychiatric, and others. The designation "expert on drug dependency" therefore has little meaning without further qualification and to form sensible conclusions it is essential to know in which areas the "expert" is truly skilled; this equally defines the important areas where opinions of the expert are in fact those of a layman. I claim no exemption in this respect and should tell you that I started by training and qualifying as a specialist in Internal Medicine and a research interest in certain chemicals in the brain led to similar training and qualification in Psychiatry as well as concurrent training and experience in laboratory work in pharmacology, biochemistry and physiology. To this I would add one thing. I believe that a multidisciplinary training in one person carries an important advantage over a coterie of individual experts from

- M.A., B.M., B.Ch., M.R.C.P., D.P.M., Associate Professor, Faculty of Medicine, University of Alberta. 
different disciplines. In such a collection interdisciplinary disputes are inevitable, e.g. the pharmacologist argues with the psychiatrist or the physiologist with the clinician, each regarding their own approach as the best. To me such disputes are meaningless and the different approaches have been integrated critically according to use and validity. By avoiding the dust raised by interdisciplinary battles we can therefore see the main problems more clearly.

Further, a background in medical research provides a common bond with the legal profession. This may provoke indignation but for both of us a great part of our professional activity is concerned with the careful appraisal of evidence. Our techniques of extraction obviously differ; you prefer your subjects standing and I usually invite mine to sit down. Sometimes I observe through the bars of a cage whereas you get into the cage with them. But always it is the evidence that is the thing and I suspect that, like me, you prefer facts which you can assess yourself rather than the opinions of the most distinguished experts (essential though these may be). My aim, therefore, will be to present to you as fairly as I can the evidence so that you may judge for yourselves. Occasionally I will voice my own opinion but will back this with reasons whenever I can and say so when I can not. Having defined the attitude of this paper I now proceed to survey current medical and legal attitudes to drug dependency.

\section{CURRENT MEDICAL TERMS AND DEFINITIONS}

The following are those advocated by the World Health Organization Expert Committee on Drug Dependence. ${ }^{1}$

"Drug. Any substance that, when taken into the living organism, may modify one or more of its functions.

Drug abuse. Persistent or sporadic excessive drug use inconsistent with or unrelated to acceptable medical practice.

Drug dependence. A state, psychic and sometimes also physical, resulting from the interaction between a living organism and a drug, characterized by behavioural and other responses that always include a compulsion to take the drug on a continuous or periodic basis in order to experience its psychic effects, and sometimes to avoid the discomfort of its absence. Tolerance may or may not be present. A person may be dependent on more than one drug."

The width of the definition of drug will be noted for it includes substances such as alcohol, food and even air and water. It might be claimed that all of us are addicted to the last three items and in ordinary medical usage the term drug has a much more restricted meaning.

\section{RECENT CHANGES IN MEDICAL ATTITUDE}

Two important trends have emerged in recent years which lead to a simplification and clarification of the subject and give deeper understanding of the above definitions.

1. A decade ago a distinction was made between addiction and habituation. Addiction was defined as a detrimental intoxication from repetitive drug consumption due to an overpowering desire or compulsion to obtain and take the drug by any means; a tendency to increase the dose; and an associated psychic and physical dependence, (i.e.

I WHO Technical Report Series 1969, No. 407. 
absence of the drug causes psychic or physical symptoms). Habituation, on the other hand, was defined as a milder condition where there was desire but not compulsion to take a drug, no tendency to increase the dose and psychic but not physical dependence. The distinctions between habituation and addiction were never clear in either lay, legal or medical usage and in 1964 World Health Organization Committees ${ }^{2}$ recommended the term "drug dependence" to cover both addiction and habituation. The concept of habituation in this connection was of doubtful value and for practical purposes one may equate addiction with dependence.

2. The second important trend was recognition that alcohol use and abuse and drug use and abuse should be considered together as presenting common problems for the following reasons: " 1 . There are many similarities in the causation and treatment of the problems involved and the concepts underlying the educational programmes required (although there are divergencies in legal provisions). 2. Drugs are often used in combinations; for example, barbiturates together with heroin or with alcohol. Also, transfer from one drug of abuse frequently occurs. 3. Many studies have been carried out on alcohol that may be applicable to drug abuse of which much less is known. 4. Although public and official attitudes to alcoholism have veered towards therapeutic and away from the condemnatory this has not yet happened to the same extent in regard to drug abuse." 3

I accept this amalgamation of alcohol and drugs as sensible and correct but the presentation of "reasons" does not distinguish clearly between biological facts and practical expedients. I would prefer to restate matters in this fashion.

Dependency on alcohol and dependency on drugs use common biological mechanisms because:

(1) there are similarities in causation;

(2) alcohol and addictive drugs are often used in combination, for example, barbiturates with heroin or alcohol;

(3) transfer from alcohol to addictive drugs or vice versa frequently occurs (substitution); i.e. psychic dependency induced by one can be satisfied (in part) by another;

(4) alcohol and addictive drugs share other pharmacological mechanisms frequently present, such as tolerance which requires increasing doses of drug or alcohol to elicit the same response.

As an example of evidence for the foregoing the following table from a paper by Mitcheson et al. ${ }^{4}$ shows the drugs used by sixty five heroin addicts who were studied at a special centre in London, England. All these addicts had used alcohol, cannabis and methadone and $99 \%$ had used both tablet and injection of amphetamine and barbiturates according to availability. To distinguish between alcohol and all the rest is an artificiality which does violence to the situation.

The recognition that similar biological mechanisms underlie both alcohol and drug dependency provides practical benefits:

1. Many studies carried out on alcoholism may be transferred to drug abuse as interim measures until more is known of the drug problem

${ }^{2}$ WHO Technical Report Series 1964, No. 273.

3 WHO Technical Report Series 1967, No. 363.

- Mitcheson et al., Lancet, 1970, i, 606. 
itself. This could include transfer of knowledge and concepts on effective educational programmes as well as help in developing realistic treatment.

Table 1

DRUGS USED BY 65 HEROIN ADDICTS

\begin{tabular}{lc}
\hline DRUG & \% ADDICTS WHO USED IT \\
\hline ALCOHOL & 100 \\
CANNABIS & 100 \\
METHADONE & 100 \\
AMPHETAMINE (TAB) & 99 \\
AMPHETAMINE (INJ) & 99 \\
BARBITURATES & 95 \\
COCAINE & 77 \\
HALLUCINOGENS & 74 \\
\hline
\end{tabular}

2. Insofar as public and official attitudes to alcoholism have widened from the purely condemnatory to a fuller and more rational understanding, it is hoped that a similar and more considered approach to drugs will replace existing prejudice and emotionalism. Figure 1 summarizes the two amalgamations discussed.

Figure 1

ALCOHOL ADDICTION

ALCOHOL HABITUATION

ALCOHOL DEPENDENCY

$\begin{array}{ll}\text { ALCOHOL \& DRUG } & \text { DEPENDENCY }\end{array}$

DRUG ADDICTION

DRUG HABITUATION

DRUG DEPENDENCY

To rephrase an august committee's report may be thought pointless or presumptuous but I have my reasons.

1. Establishment of the biological similarity is of considerable importance for it endows a concept with a stability independent of social criteria. Let me illustrate this with a familiar example. Any competent doctor can diagnose pneumonia whether he is in Britain or Russia or America or Canada or Japan. It is a biological state independent of social or cultural significance and if it gives rise to a delirium in which a patient commits some crime it will be accepted under most legal systems as a possible defence for social transgression. It should need no emphasis that those who employ social criteria to define physical or mental health or disease inevitably encounter difficulties when diseases so-defined are proposed as a defence for other social activity.

2. The second reason for my revision is to avoid prejudgment of issues. In the original version it is assumed that condemnation should be rejected and a therapeutic approach embraced. There is no evidence at all on which to reject condemnation out of hand. Its role has still to be studied but such study requires supplementing with other 
alternative solutions including (but not confined to) therapeutic. I would also prefer the term management to therapeutic for the latter suggests benefits which we are in no position to offer at the present time.

\section{LEGAL ATTITUDES}

In discussing these it will be understood from my earlier remarks that this is not an attempt at legal analysis but presents the viewpoint of a scientist concerned with the subject of the legislation. From this aspect the laws are federal and tripartite, but Alberta, being a superior province, adds provisions of its own.

1. Food and Drugs Act and Regulations. Three schedules are important. Drugs listed under Schedule F, Part 1, require a doctor's prescription and this list includes etryptamine, mephentermine, mescaline, methylphenidate, paraldehyde, phenmetrazine, phentermine, and pipradol, most of which are amphetamine-like substances; but a hallucinogen (mescaline) and a hypnotic (paraldehyde) are also included. Part 2 of the same schedule F contains drugs similarly restricted but which may be obtained without prescription if labelled "for agricultural use." Addictive or possibly addictive drugs herein include meprobamate and tranylcypromine which has an amphetamine-like effect. ${ }^{5}$

Schedule $G$ comprises the so-called controlled drugs, the amphetamines and barbiturates which require a practitioner not only to prescribe but to keep records of all transactions.

Finally, Schedule $H$ lists thalidomide which was so disastrously used in pregnant women and four hallucinogens, lysergic acid diethylamide (LSD), DET, DMT and STP (=DOM=4, methyl 2, 5 Dimethoxyamphetamine). The last three have no medical application that I know of and medical indications for LSD and amphetamines are limited. The remaining drugs in Schedules $F$ and $G$ are in common medical use and the benefits, I believe, outweigh the hazards, provided medical supervision is present.

The Public Health Act in Alberta provides an additional control on hallucinogens and prescribes penalties for misuse.

2. Narcotics Control Act 1961

The drugs involved here include the opiates (such as morphine, heroin, and synthetic derivatives) and cannabis. The medical use to be made of cannabis so far is negligible but the use of opiates as analgesics has provided far more medical benefit than barbiturates or amphetamines. Yet even at a time when medicine needed to lean heavily on the palliative effects of such drugs the law has prescribed severe penalties for misuse. It should interest all Canadians to trace the role played by Mackenzie King in the development of narcotic legislation both at home and abroad as well as the powerful influence of the Edmonton magistrate Emily Murphy. An account will be found in Whitaker's excellent book. ${ }^{6}$ The Narcotics Control Act of 1961 was enlightened legislation in that it recognized the need for medical treatment and provision of special centres such as those in Matsqui

s One's curiosity on the possible uses of an antidepressant in veterinary practice is further increased by the inclusion of disulfiram or antibuse which is used in the aversion treatment of human alcohol addiction. Although one might speculate that alcohol is already a problem in cows the principle veterinary use is to treat worms!

- Whitaker, Drugs and the Law (1969). 
and Ontario. The disquieting aspects concerning the liberty of the individual are also well dealt with by Whitaker and are important enough to be the subject of separate and no doubt continuing debate. ${ }^{7}$

\section{Alcohol}

The third part of the legislation concerned with the dependency problem comprises the liquor laws and those sections written into the laws on other matters where alcohol may be a potential hazard, e.g. in driving. The American experiment has shown that prohibition of alcohol was a failure. Although some good came of it (the incidence of cirrhosis dropped) the harm it did in terms of society is incalculable. Most countries now restrict hours of sale, restrict sale to adults, tax it heavily, and, in Canada, take the retailers' profits as well.

In sum the law has developed three approaches to a problem which medicine now views as essentially a single one. And paradoxes occur.

\section{PART 2-INCIDENCE OF DRUG ADDICTION IN SOCIETY AND CAUSES}

\section{EXTENT OF THE PROBLEM}

It is estimated that there are some 250,000 alcoholics in Canada and addiction to drugs occurs in $0.02 \%$ of the population which gives a total figure of approximately 4,000 . As Whitaker $(1969)^{8}$ points out estimates such as these recurrently bombard our ears and eyes through the mass media but such numbers may convey an accuracy which they do not possess. The validity of the various types of data is worth a closer scrutiny.

Let us start with first principles. To estimate the true incidence of any condition we need two things: First, a test which is as near $100 \%$ accurate as possible and second, a means of applying this test to every member of that population. In the case of drug dependency, methods for measuring drugs in body fluids, urine, blood or breath of a subject exist for all the commonly abused drugs with the exception of marijuana. One example familiar to you is the breathalyser; more laborious, but more accurate methods are available for the opiates, barbiturates, the amphetamine-like substances and LSD. However, because of the time involved, applying such tests even to a small sample of the total population is at present unpractical and has not been done. Should testing become feasible there would immediately arise the problem of obtaining a truly representative sample. A further deterrent is the ruling that examination of a subject's urine without consent is an assault. Yet only by such methods will we obtain any really valid scientific data on the extent of drug abuse.

At present, however, we have to rely on much less precise data:

(1) Estimates by various experts are common and have already been

\footnotetext{
1 From the biological and medical point of view I have no hesitation in saying that Whitaker's book is excellent. My comment on the legal aspect has only layman value and to temper this I should quote the opinion of an eminent legal authority who found the book biased against the law. It is nonetheless to the enduring credit of Whitaker and those like him that they have been responsible for mobilizing opinion on civil liberties. And that the Civil Liberties Committee of the Canadian Bar Association adopted the resolution by Ketchum of Edmonton (on behalf of the Alberta section) which stated that writs of assistanco were "illegal and repugnant" and that the whole Bar Association almost unanimously endorsed this resolution on September 4, 1970. (Edmonton Journal, September 3 and 5, 1970).

- Supra, n. 6.
} 
cited. Although it may be claimed that such experts are disinterested I think this is difficult and margins of error in any case are enormous. They are better termed "guesstimates."

(2) Less subjective is the record of admissions to mental hospitals for drug addiction. (Fig. 2). Such data have obvious limitations. Only a minority of drug addicts need admission to mental hospitals; the

Fig. 2

NEW ADMISSIONS OF NON-ALCOHOLIC ADDICTS TO CANADIAN MENTAL HOSPITALS

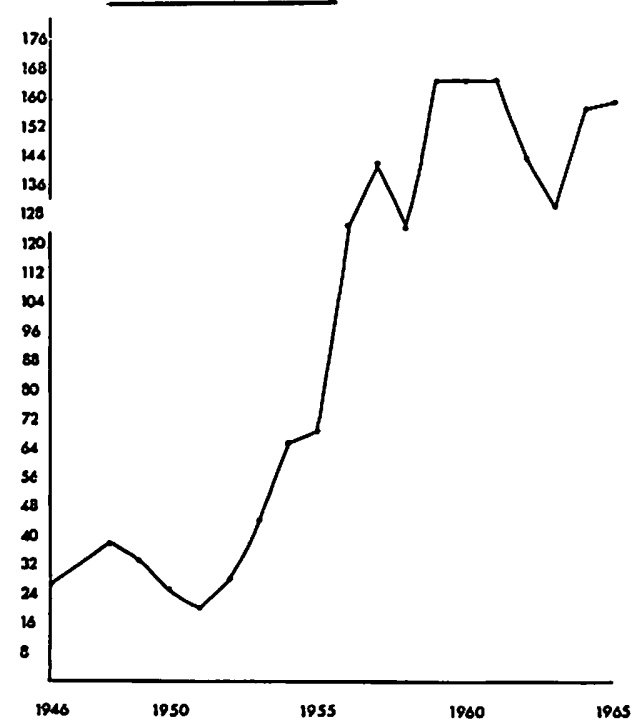

AGE GROUPS OF NEW ADMISSIONS

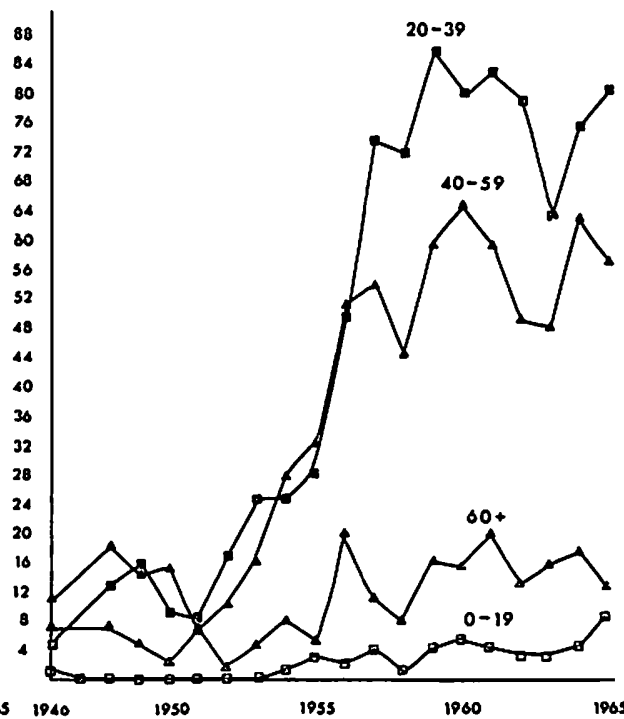

numbers admitted reflect not only the incidence of drug abuse but also differing admission policies on the parts of superintendents, other hospitals, governments and the like; females are probably overrepresented because males are more resistent to admission to avoid loss of job and so on.

(3) A third type of data will be much more familiar to you, namely, numbers of prosecutions made. These again obviously have limitations but also have much use. Fig. 3 shows that in Canada under the Narcotics Control Act prosecutions have risen progressively over the last five years and this rise particularly affects cannabis whilst opiates remain low. Table 2 shows that, taken across Canada, British Columbia is currently the problem area but Alberta can no longer be complacent with a total $25 \%$ higher than the national average in 1968.

\section{Table 2}

\section{NARCOTIC PROSECUTIONS}

per Million Population

$$
1967
$$

All Canada 
Such evidence naturally depends on the zeal with which the police carry out their duties which in turn partly depends on social pressures, (not

Fig. 3

\section{NARCOTIC PROSECUTIONS IN CANADA}

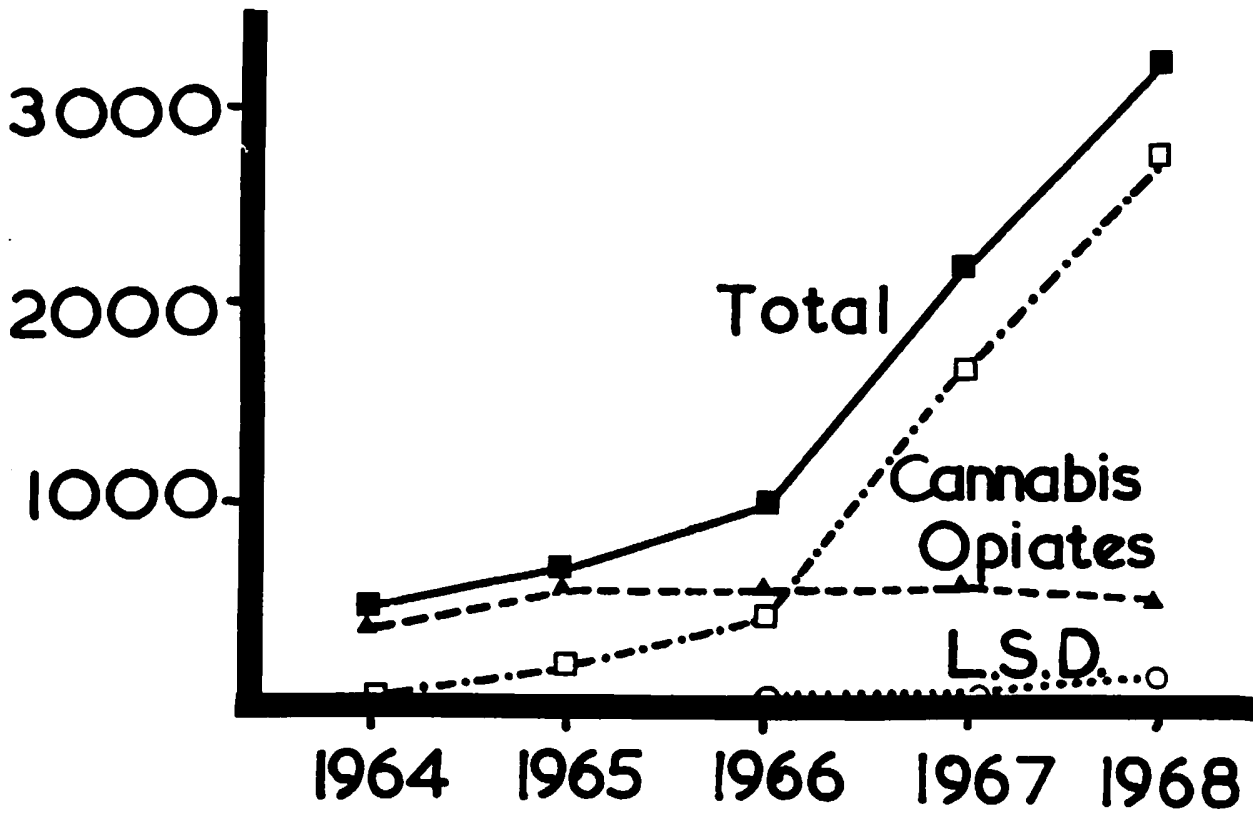

least from the bench), partly on the numbers of police available, partly on the individual officers and partly on other things. As absolute numbers such data have little use but they do show trends. However, in Canada things were changed by the Narcotic Control Act in 1961. On the other hand, until the introduction of the 1967 Dangerous Drugs Act there has been no change in British legislation and figures are available from that country for a much longer period of time. To some extent the data are unique and, I believe, carry a lesson for Canada. This I will leave you to judge yourselves.

To start, Fig. 4 shows the overall figures for prosecutions in great Britain for various drugs from 1921 to 1966-almost half a century. The prosecutions of course represent an unknown proportion of total addicts and the absolute numbers depicted in these graphs have uncertain significance. However, the critics who complain on these grounds miss a much more important point. That is that such graphs clearly show changes in time. Three can be observed in Fig. 4. (1) Between 1940 and 1945 there was a temporary upsurge in opium offences. (2) In the late 1950s, cannabis offences (which had increased post-war but then levelled out) again started to increase but more rapidly. (3) This increase was followed about five years later by an increase in "manufactured drugs" which includes all substances in the Narcotics Control Act of Canada except marijuana.

The first increase was accountable entirely by the temporary influx of Chinese. 
The second increase in cannabis offences may be partly attributable to the movement which Timothy Leary started. Although names have changed, this subculture continues to exist and have impact. Their main themes are love and travel (of the kind done without moving). Those who gibe tend only to see the undesirable effects of the movement but good features are there also. I am all for love. And I admire those with the courage to express dissatisfaction with the wrongs in society irrespective of personal consequences. I do not admire the defeatism of dropping out. The lawyer James T. Carey in his book, "The College Drug Scene" depicts the characters found in the drug subculture at Berkeley. ${ }^{9}$

The third increase in opiates apparently came out of the blue. There appeared to be no obvious social precipitants at that time and

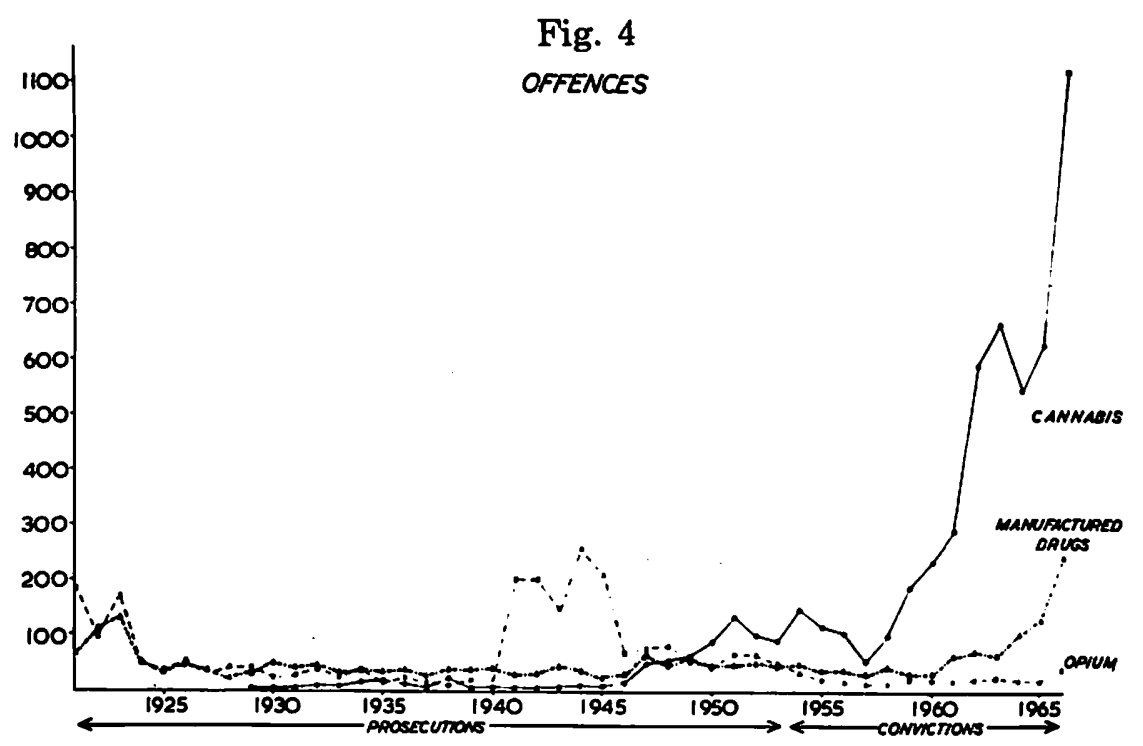

no changes in legislation in Britain. The impending changes in Canada's legislation might possibly be suspected to have led to immigration of addicts to the U.K. but in fact (as subsequent figures will show) Canadians did not account for the rise. The increase further seems a true one for there was no material change in methods of detection or in numbers of officers employed.

I wish to analyse this aspect in some detail for it is, I believe, most relevant to Canada. Although Fig. 2 shows the curve for opiates remaining comfortably level, an examination of Figs. 5A and 5B will show that if Canada follows the British pattern a rise in heroin addiction may be expected.10 For reasons which will be documented later heroin addiction is by far the most serious category of all addiction and anything that can be learnt about it from other countries deserves notice.

The British data on opiates in this regard are of unique help for in addition to prosecution figures discussed hitherto the Home Office in Britain kept an index of all prescriptions for opiates including heroin, which has long been banned in the States and Canada. Further, doctors

- Carey, The College Drug Scene (1968).

10 This prediction, unhappily, is being proven true in the months since it was made. 
Fig. 5A

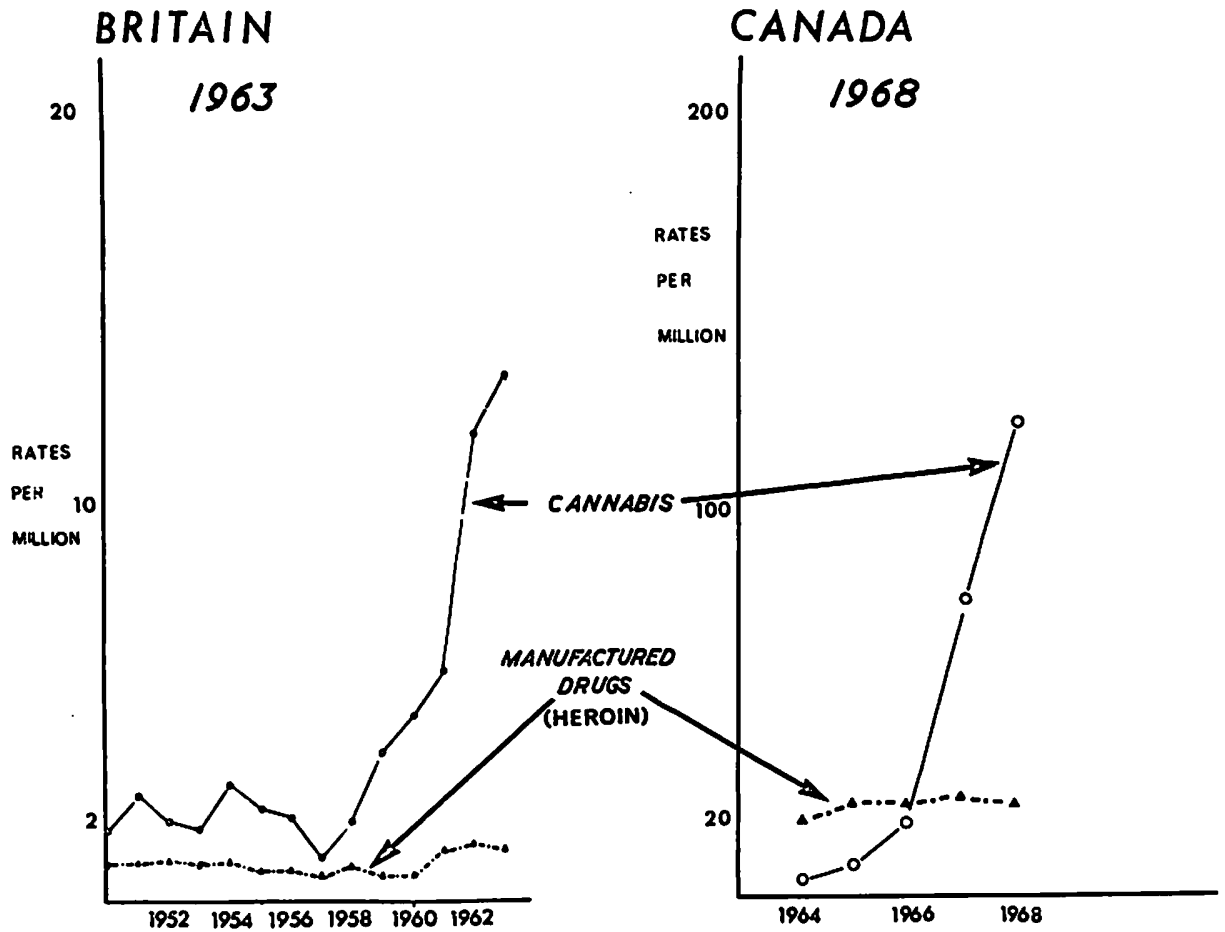

$1952195419561958 \quad 19601962$

Fig. 5B

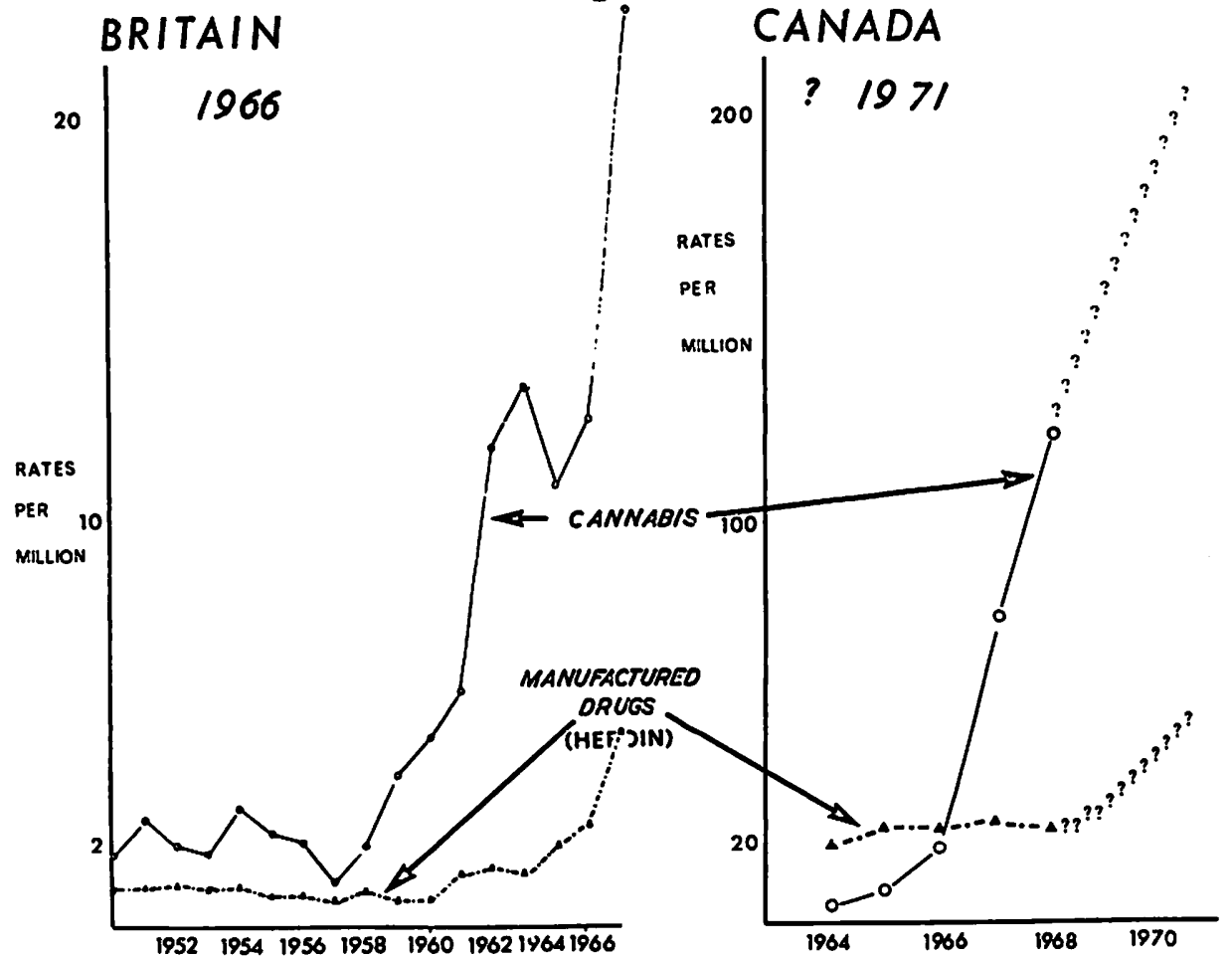


could prescribe such substances freely until 1967 and it was easy for heroin addicts to obtain supplies for a few cents and even free. Under such conditions black market suppliers could hardly hope to make a profit and one thus had the unique situation of being able to keep track of nearly all addicts to "hard" drugs. The index figures to 1967 are much better guides than other data in this field.

First, consider the type of opiate involved (Fig. 6). It will be seen that in the early sixties a rise in index cases started, chiefly in heroin, but associated in part with cocaine. However, cocaine addiction never

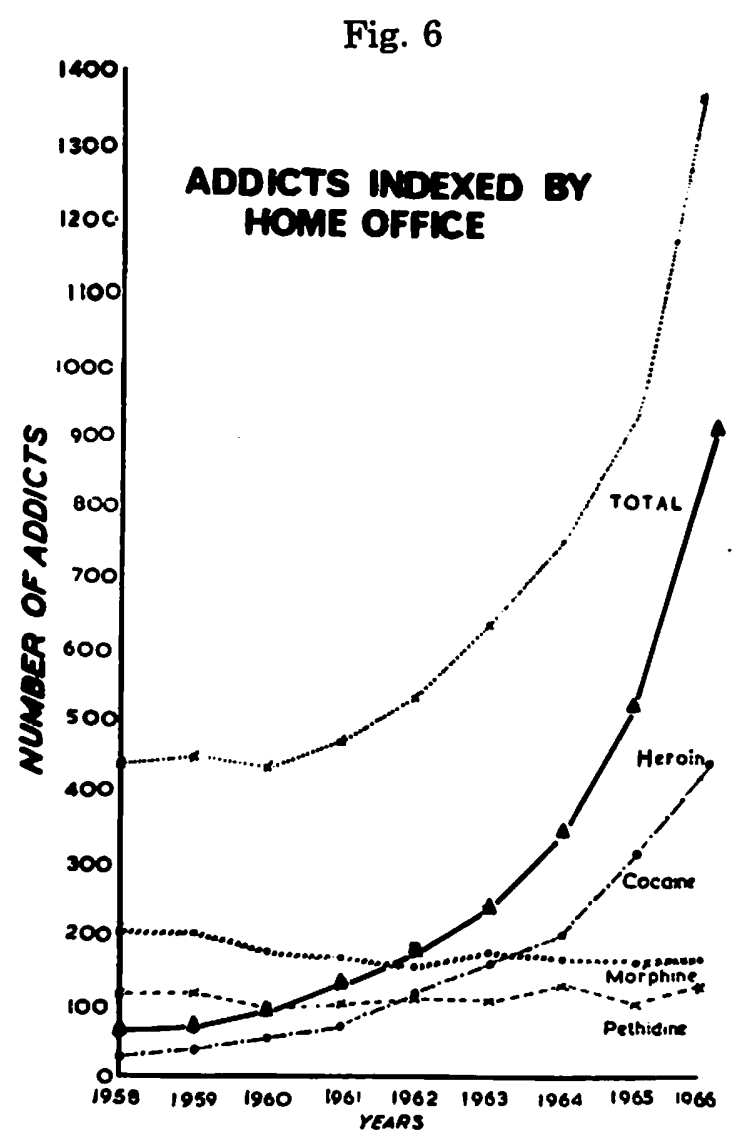

occurred alone and it was always taken as an adjuvant to heroin (known as "H \& C"). Nowadays cocaine is being replaced by amphetamines. Heroin, therefore, is the main problem.

Subsequent graphs show some factors related to the rise. First, it impinges chiefly on the young adult and adolescent (Fig. 7). Second, it is now predominantly a male prerogative to be addicted (Fig. 8). (Previously it was the middle aged female who was the most likely opiate addict (Fig. 9). As I mentioned earlier this rise in addiction could not be ascribed to immigration of Canadian citizens fleeing impending legislation (Fig. 10) and has to be viewed as an indigenous problem, nor can it be ascribed to the medical profession becoming addicted (Fig. 11). (This class of addicts in Canada is known as the professional addict which I think is an unfortunate term. It suggests graduation with 
Fig. 7

FACTORS ASSOCLATED WTH INDEX CASES

1. AGE

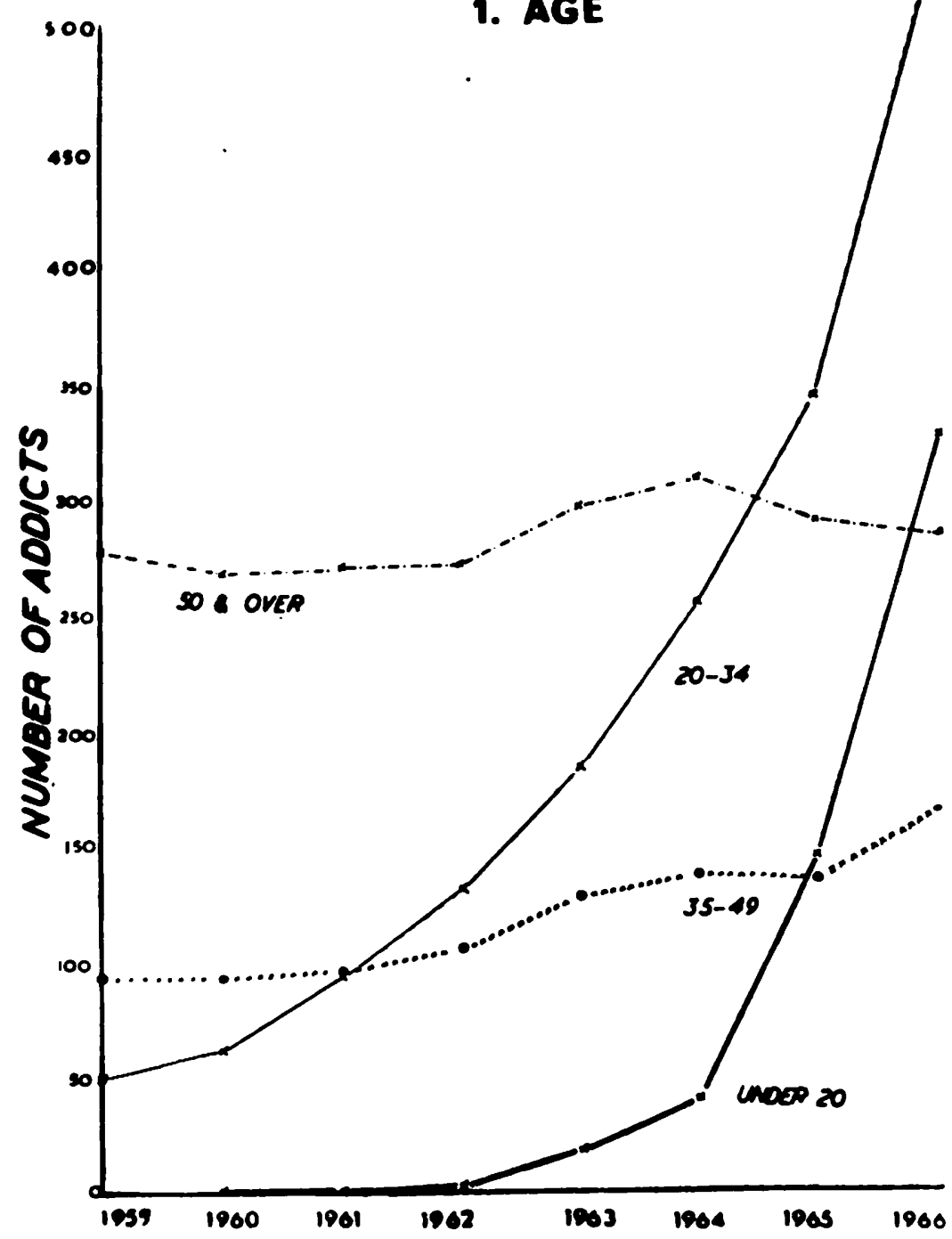

a B.A. in addiction and specializing with an M.A. or Ph.D. in heroin). Finally, Fig. 12 shows therapeutic addiction. This is induced by doctors when drugs are given, say, for what is thought to be a terminal illness but from which the patient recovers as a healthy addict. Such cases have shown virtually no change over the years and the increase can be seen to be non-therapeutic in origin. (The therapeutically-induced addict is called a "medical addict" in Canada and again I must cavil at such terminology which makes nonsense of English and is seriously misleading).

The next graph (Fig. 13) shows the incidence over the years of new cases, relapses ("new-old") and drop-outs. The curve for new cases will readily be recognized as an exponential one which is com- 


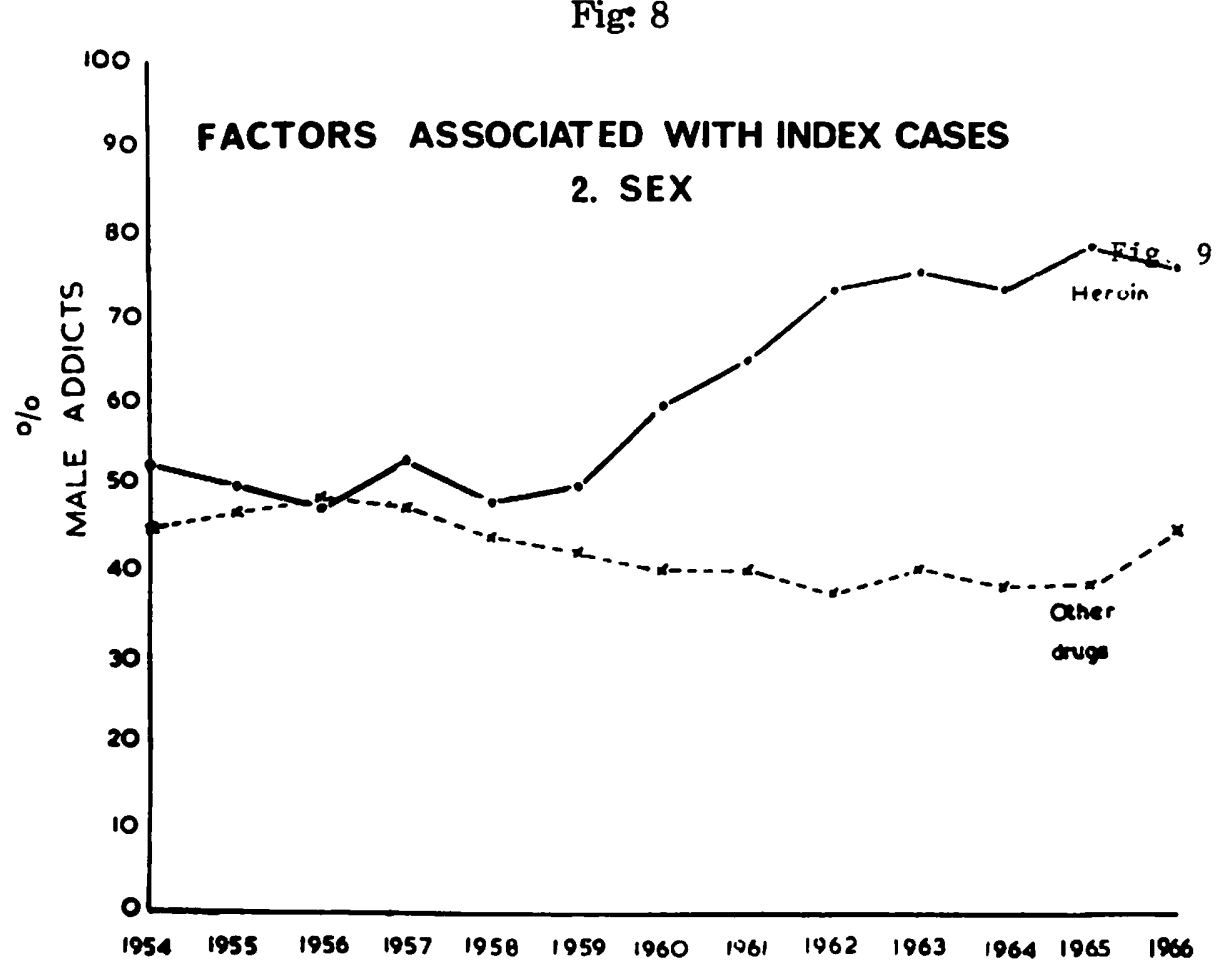

Fig. 9

FACTORS ASSOCIATED WITH INDEX CASES

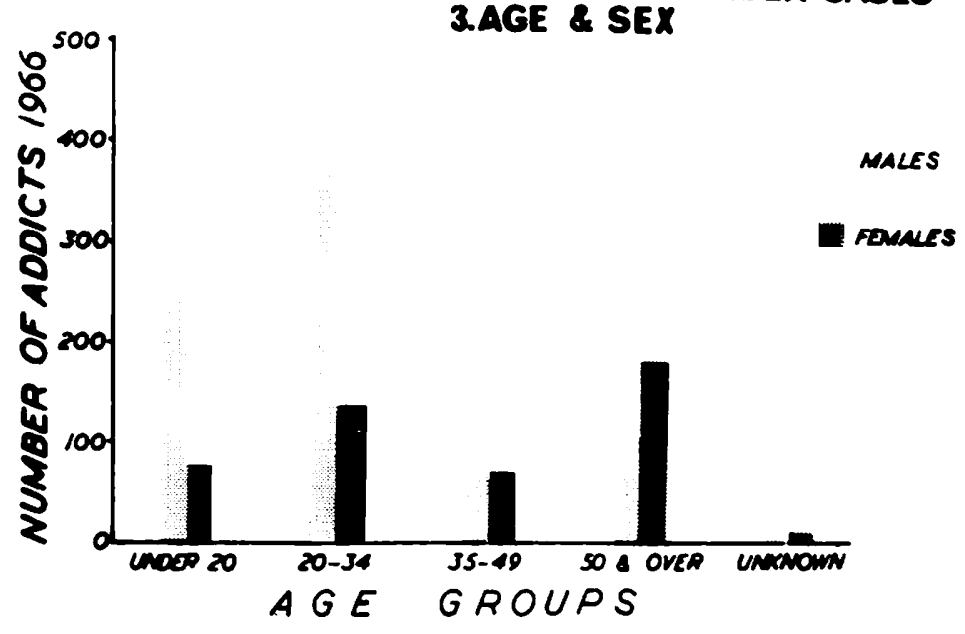


Fig. 10

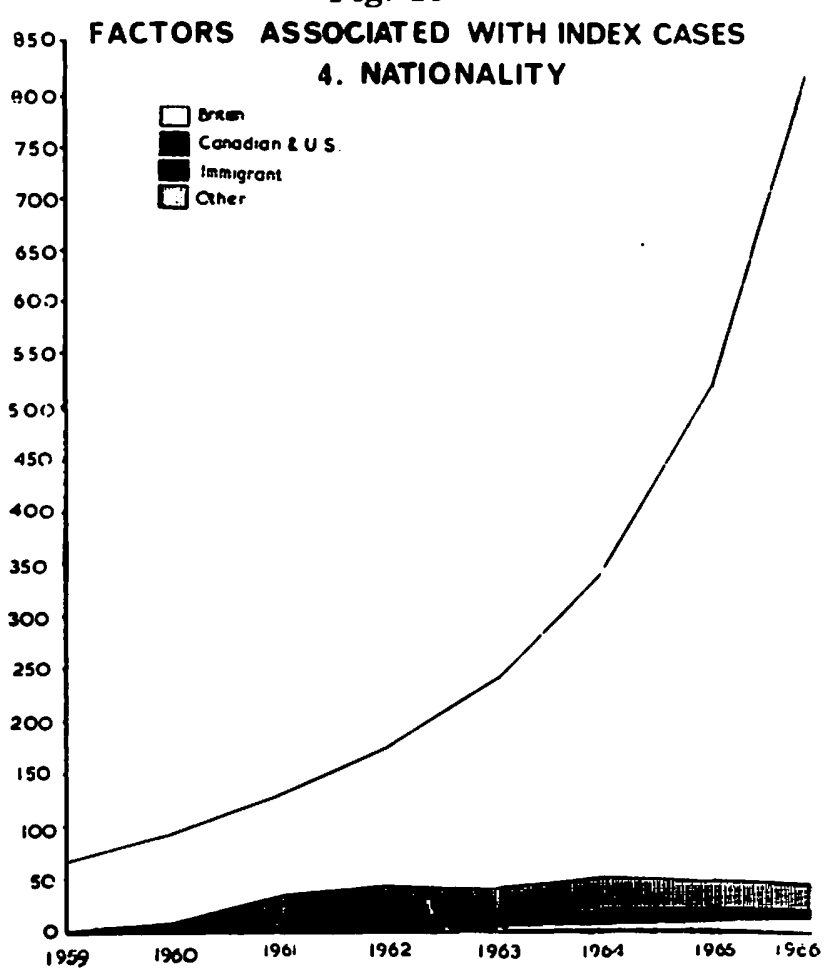

Fig. 11

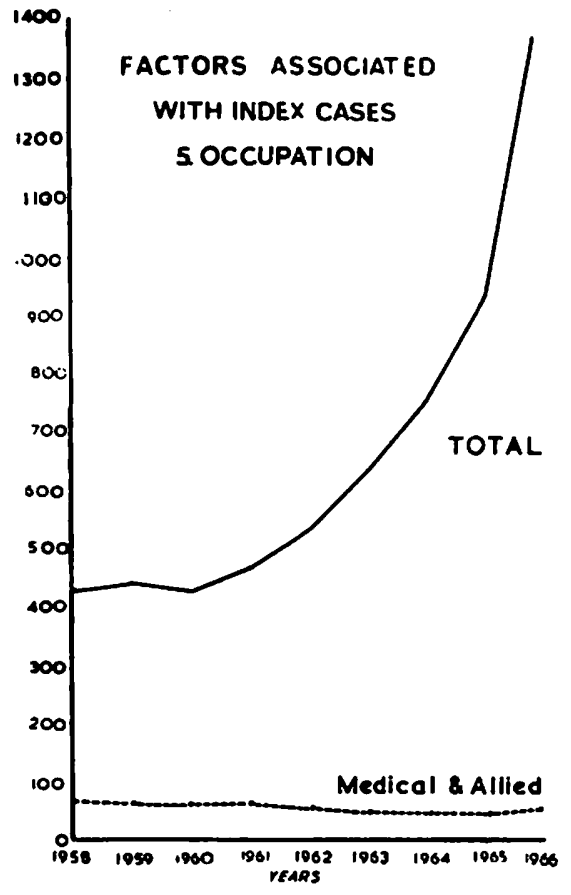


Fig. 12

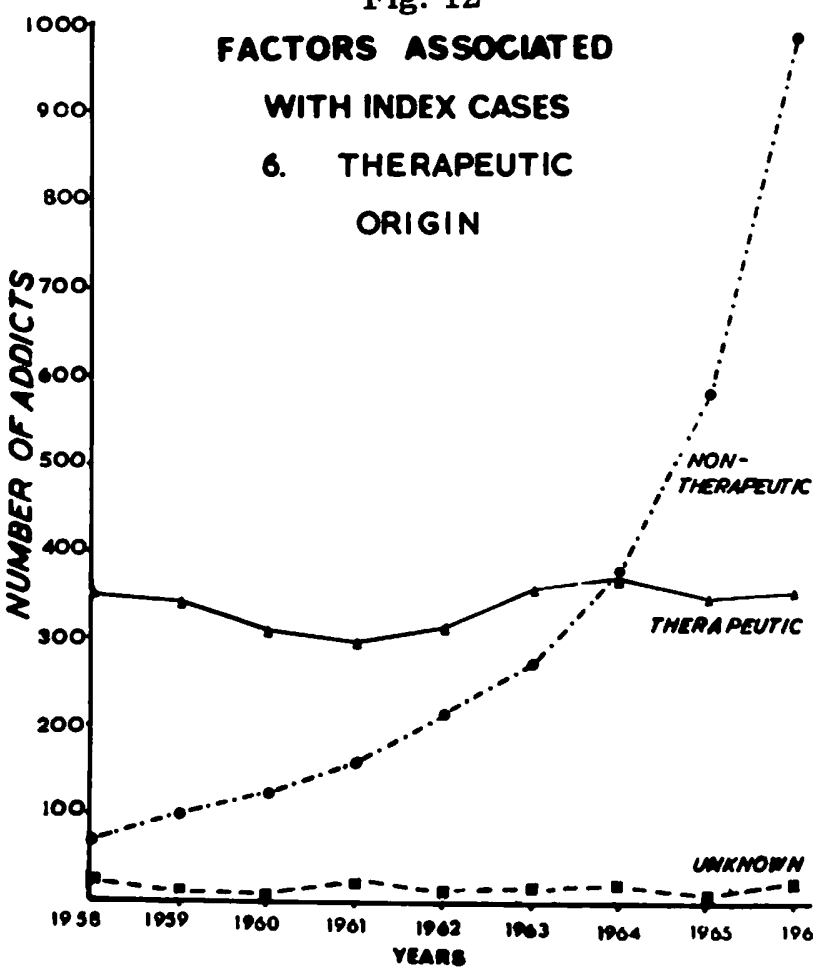

Fig. 13

HEROIN INDEX ONLY

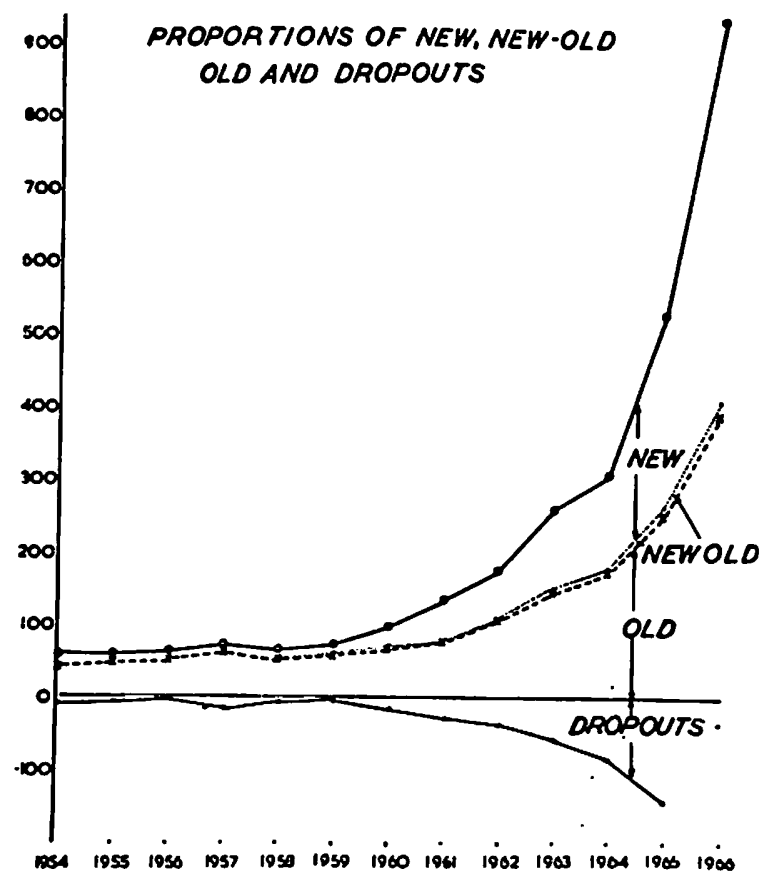


monly seen in biological sciences, particularly as a growth curve. It denotes that the rate of increase is proportional to the total numbers at any particular time or in mathematical terminology it is a firstorder process and follows a first-order differential equation. One peculiarity of this type of curve is that if one plots the logarithm of the quantity increasing the "curve" becomes a straight line. Fig. 14 has been so plotted and now shows clearly that the rate of increase is ap-

Fig. 14

\section{HEROIN INDEX ONLY}

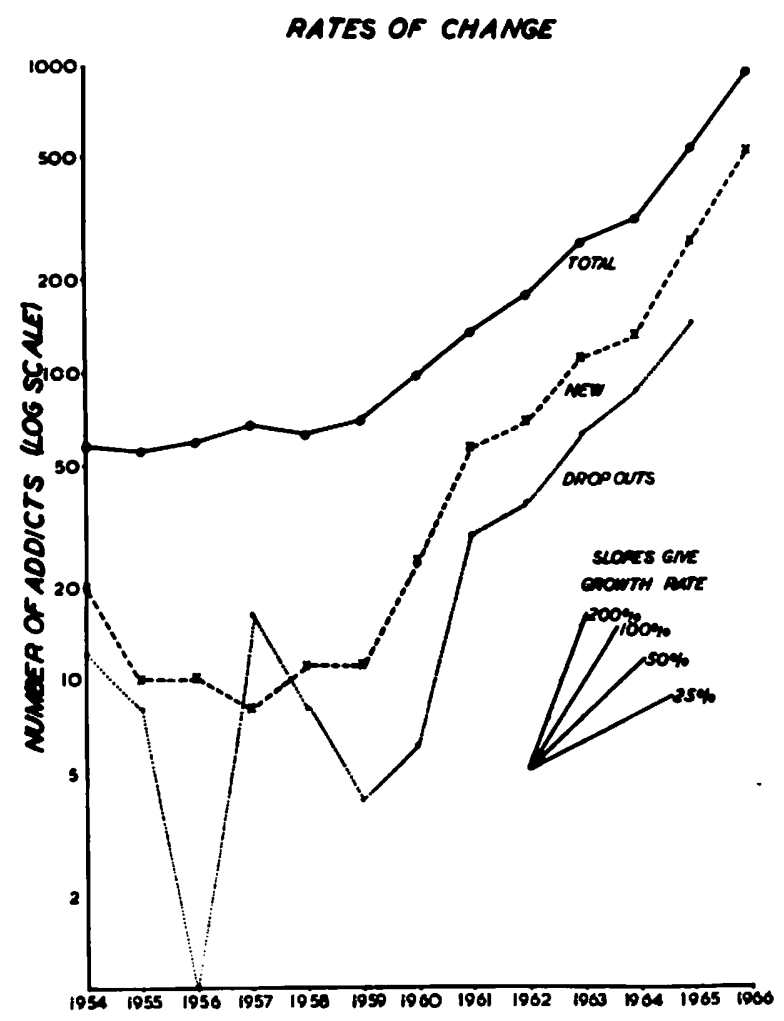

proximately $100 \%$ for both new cases and total (i.e. doubles every year). As at any given point in time total cases outnumber drop-outs, so must the total population increase exponentially as well.

\section{CAUSES OF UPSURGE}

The upsurge I believe is clear. Why? Suggestions are plentiful.

1. Response of a criminal minority or lower classes to oppression or persecution. Partly true perhaps in the U.S. (in 1965 narcotic addicts were $52 \%$ Negro, $13 \%$ Puerto Rican, 6\% Mexican). But not true in Britain, nor for University groups in the U.S. The brunt appears to fall on white adolescents of middle class and intellectuals.

2. Decadence of modern youth. The adolescents and children who get hooked are I think no different from the rest of their generation and they are not particularly vicious or indolent. It is also true 
that through the ages the young generation has always been deplored whatever its habits.

3. Over-prescribing by doctors may, perhaps, facilitate the increase in numbers but $\mathrm{I}$ cannot see a sudden change in prescribing habits as a cause of the increase. This is confirmed by the graph on therapeutic addicts (Fig. 12). At most it met a demand created elsewhere. And even in the famed British National Health Service marijuana has never been obtainable on prescription at any time. So we must clearly search elsewhere.

4. Immigration, and

5. Occupation, must both be rejected as Figs. 10 and 11 have already demonstrated.

\section{Consider the following:}

1. A striking increase in marijuana offences occurred without obvious environmental precipitants in the late 1950s. Four to five years later this was followed by a steady increase in addiction to opiates almost exclusively heroin.

2. 99\% of all heroin addicts admit to using marijuana and the same proportion admit to amphetamine.

3. Seizure of the illicit drugs by the various law-enforcement agencies show that they are all machine-packed. This applies to the marijuana leaves, the resin from marijuana (hashish) and to the heroin impounded. Machine packing is customarily the prerogative of bulk production in factories. The hashish resin is wrapped in stockingette coverings which bear particular trademarks exactly equivalent to the different brands of cigarettes available. These trademarks guarantee various degrees of idyllic satisfaction and the producer to some extent gives a warranty for his product to the consumer.

4. In Britain, teenagers and young adults emerged in the $1950 \mathrm{~s}$ as those with money to burn. Large wages were relatively easily obtained in factories and in labouring jobs by youths of 17 or 18 who had minimal responsibilities or liabilities. To a lesser extent this is also true of girls. That the market was extensive and lucrative can be readily seen in the policies of the clothing and pop music industries the bulk of whose output became concentrated in this area.

5. At any large gatherings of young people in the late $1950 \mathrm{~s}$ free supplies of marijuana and amphetamine-type drugs were mysteriously made available. Teenagers told of older men carrying around sacks of "purple hearts" or later "French blues" and dumping them on the crowds. Teenagers indeed tended to collect in these throngs for the sake of obtaining free supplies of this sort.

6. Most young male heroin addicts give a similar account of the way their addiction started. In the permissive atmosphere where amphetamines were regarded as a "giggle" they were invited to have a "fix" by a significant figure in the "in-group." Most refused this initial invitation and it was then repeated as a challenge "you're too scared" or "you're not man enough." It takes a very strong character indeed to resist such a slight to courage of a spirited youth. 
7. The "hooked" addicts report that to obtain further supplies the cost is high but not usually ruinous; however, more than money is asked for if supplies are to continue; these will only be sure if the addict introduces a fresh victim to the ring.

Let me now indicate the degree of validity which these items possess. Items 5, 6 and 7 are the most questionable. They are derived from the reports of adolescents and young adults (by no means all addicts) seen at the Maudsley Hospital by myself in the late fifties and early sixties. An account by a single individual would be of little weight but when the same story is reported by several youths seen at widely different times, living in different parts of London, and belonging to different "gangs" any grounds for collusion seem remote and reports indicate a standard pattern. I think these youths trusted me; the hospital's reputation was a high one whatever the walk of life and whether legal or illegal; the facts reported had no particular significance, e.g. in enhancing self esteem, or as a means of getting them out of trouble; in short by all criteria I can judge by they seem to be reporting truthfully in widespread and standard practice. I should add that the Maudsley Hospital is an ultimate referral point in Great Britain and sees patients not merely from London but from the whole country.

Items 1 to 4 are easily and completely verifiable through Home Office and other data and various obvious economic indices. At this point I now invite you, as eminent jurists, to consider the evidence. If your conclusions are the same as mine we will have identified one of the main causes of the drug problem-at least in Britain. It is also possible to make a reasonable working hypothesis which accounts for the rise of heroin addiction following the rise in marijuana; which accounts for the predominance in young males; and which explains the exponential growth rate of new heroin addicts whose numbers double every year.

\section{My own conclusions are these:}

Item 4 indicates an obvious lucrative market for any business concerned with consumables. The nature of the market further shows that profits will be optimized by restricting prices to the maximum obtainable on a realistic basis from the average consumer and concentrating effort on means of obtaining as many consumers as possible. Items 3 and 5 indicate that considerable capital is involved.

Is it, then, too far fetched to propose that the following sequence occurred? A lucrative market with surplus money was identified in Britain. This market was "softened up" (very appropriately) by "soft drugs." When sales resistance and fear of drugs had been overcome the progression to heroin and perhaps LSD was instigated. The heroin addict must be regarded as the most certain of the investments in this field in spite of the wastage due to deaths.

Why the male predominance? Partly perhaps because the male earner had more money available than the female but whether this was the reason or not males were subjected to a special sales technique-the "challenge technique." The heroin "fix" has replaced earlier tests of supposed virility, such as doing a "ton" (100 m.p.h.) on a motorbike, carving someone up with a flick knife, or in much earlier times (my own), getting drunk and pinching a policeman's 
helmet. Females are much more sensible about such challenges and through the centuries seem to have deviated little from their main biological role; for them "getting hooked" means to a man.

The exponential growth rate is explicable in terms of another technique, the so-called cell technique. Unlike the dope pusher of fiction who had a few wealthy victims whom he "bled white" the heroin entrepreneur of today is concerned with rapidly increasing his market. This can be ensured by telling the addict that further supplies will depend not only on money but also on the introduction of another victim to the ring. The graphs indicate that the requirement asked for is about one fresh victim a year. All being well (all being bad), the single victim by the end of the year will have introduced another to the net to ensure his own heroin supply. The pair in another year become a quartet, then octet, etc. The social cell in fact mimics the cells of body tissues, and more particularly the cancer cell, where multiplication proceeds unchecked by the body.

\section{PART 3-DRUG ADDICTION IN THE INDIVIDUAL AND OUTCOME GENERAL}

Having discussed some of the mechanics of supply we must now turn to the consumer's end for consumer demand is the other half of a single problem. It is, indeed, the aspect on which the bulk of the literature concentrates.

The effects of addictive drugs are clearly important in areas beyond the special interests of pharmacology and therapeutics. These drugs are now diseases not treatments and from a doctor's point of view accurate diagnosis of drug effects is doubly important for not only is the medical welfare of the patient involved but also his legal welfare. Second, from a lawyer's point of view there is also a twofold interest. One consideration is the validity of evidence which may be adduced to support or disprove a diagnosis of addiction; Canadian law prescribes treatment for the addicted trafficker whilst the non-addicted may face life imprisonment. The law is also concerned with crimes committed under the influence of drugs which touches on the profound problem of responsibility.

\section{MEDICAL STATE IN USERS NOT TAKING DRUGS}

Let me say at once that there is nothing to distinguish the occasional user of drugs during intervals when he or she is not under their influence. They are the same as you and I. There are no particular characteristics which betoken a potential addict or user anymore is known. It is also true that in the case of both drug addiction is a teetotaler or not. This analogy, incidentally, illustrates the use of amalgamating alcohol and drug addiction as a single concept, for our experience with alcohol can thus give guides in the more unfamiliar areas of drug addiction which can be helpful stopgaps until more is known. It is also true that in the case of both drug addiction and alcohol addiction persistence in the habit may lead to social degradation, loss of jobs, thefts of money to buy more supplies, and so on, which has been depicted in graphic detail by many novelists. It is equally true that for most who use alcohol this never happens. We follow Winston Churchill rather than Dylan Thomas. I regret that I cannot cite a quotable teetotaler. Of course, various 
addicts readily recognize each other but this is not because of objective biological of physical characteristics. Recognition depends entirely on verbal cues; use of the current slang in the drug subculture is the recognized entree to acquaintanceship just as it is with homosexuals (for it is only the lunatic fringe of homosexuals who affect blatant effeminacy caricatured on the stage).

\section{ACUTE EFFECTS OF DRUGS}

In contrast to the lack of signs between doses there is a superabundance of drug effects and to a large scientific literature is added a lay one which with few exceptions is colourful but untrustworthy, venal in motive, and mostly illiterate, whilst the exceptions to this (such as De Quincey and Huxley) limit accounts to the reactions of one person. I offer however some simplification which may help in this exotic jungle and suggest two phases of importance-euphoria and delirium.

\section{(a) Euphoria}

People take drugs for many motives ranging from therapeutic to suicidal. In the case of drug addiction however the desirable effect sought from drugs is a feeling of well-being, contentment, or satisfaction with freedom from worries about past, present or future. This state of good mood or elevated mood I subsume under the term euphoria.

The evident importance of this state leads me to suppose that some knowledge of the mechanisms normally at work will aid in understanding much of what follows. To be consistent with my plan I must concern myself for a moment with the evidence which is substantial, scientific, and complex for the body-mind problem is involved. Discussion here would therefore take us too far off course, but those interested will find documentation of references in the footnote. ${ }^{11}$

Elevation of mood in normal man depends on two things; (1) a chemical which is largely found in parts of the brain which are old in evolutionary terms and (2) a particular psychosocial setting. The chemical is made from amino acids which in turn are derived from proteins in our food. In structure it is an amine which means that it has some resemblance to ammonia and like ammonia is an alkaline substance. Various amines are to be found in the brain, such as noradrenaline, (norepinephrine), tryptamine, and so on, and are potent in minute doses; they are important in controlling a variety of basic functions, such as being alert and being asleep, eating, drinking, blood pressure and so on.

Both chemical and psychosocial factors are necessary causes but neither is sufficient. This may be best illustrated by depressive illness in which mood is pathologically lowered and may remain so for several months unless treated. One form of this condition is due to a deficient quantity of amines in the brain. In such circumstances treatment by altering psychosocial factors (a holiday or change of job are common and sometimes disastrous suggestions) will bring little benefit and measures designed to restore the levels of chemicals in the brain must be used. In contrast, other types of depressive ill-

"Dewhurst, Amine function in health and disease. Studies in Psychiatry, (1968) Oxford University Press, ch. 14. 
ness are primarily due to a psychosocial disturbance which may be irremedial e.g. bereavement. In such a situation attempting to increase the stores of chemicals in the body will produce little result, for the psychosocial upset remains. I hasten to add that the subject does not remain depressed for eternity for in time he relearns and adapts to the loss.

This sense of well-being sought through drugs by modern sophisticated man is more than the gratification of food, sex, and the like, and is normally the result of two particular psychosocial circumstances, namely a sense of achievement experienced as an individual and second, social approbation. I believe all of us here can recall marvellous moments in our lives when we've been on top of the world. We may have just got a coveted job or promotion, passed an exam, done a hated rival in the eye, starred in a hockey match, and so forth. The sense of personal satisfaction is made all the sweeter where social approbation is joined to it. It is unfortunately true that such moments are fewer, far fewer in most of our lives, than we would like. We achieve without perhaps receiving the social approbation or (and to some even worse,) we see a colleague receiving the social approbation without achieving; again we may have no capacity to achieve anything and realise it; or we may have capacity and opportunities to fulfil it are blocked. And even if we were Leonardo da Vincis we could not turn out a Mona Lisa once a week anymore than Einstein could produce a theory of relativity every month. Yet most of us seem to have a need for the refreshment and increased motivation of such moments and we turn to means at hand whereby similar but milder experiences may be obtained artificially.

Remembering that normally we need chemicals and psychosocial factors for euphoria, drugs of addiction simulate such experiences in various ways. The amphetamines mimic very closely the actions of the naturally occurring chemicals in the brain to produce euphoria (if the psychosocial setting is right). Other drugs affect the normal mood processes indirectly. The majority (including alcohol, barbiturates and the opiates) depress higher nervous centres and make us less critical, dull painful memories, worries about the future, and dissatisfaction with ourselves at present. Finally, a small group of drugs, the hallucinogens, produce the euphoria in a more subtle manner still by distorting perceptual processes and even inducing hallucinations (impressions firmly believed to be real yet without external stimuli). Euphoria apparently results from the pleasing sights but as with the previous group there is some depression of cerebral activity which contributes as well. LSD and marijuana can be placed in this group.

The pleasurable experience, therefore, is the crux of the recurrent desire of addiction. I will emphasize again that the psychosocial circumstances are as important as the chemical. Indeed where marijuana is smoked in groups or alcohol taken at a party or when people first learn to smoke the chemical action may be negligible or even produce dysphoria and the cummunal setting is all. This is clearly demonstrated by the fervour engendered in a revivalist meeting against the "demon rum" where social stimuli can produce euphoria and even ecstatic states which surpass those engendered by alcohol. 
Again this can only happen when the normal store of chemicals in the brain is present.

After the first pleasurable experience the addict seeks to relive it as soon as possible. Frequently, to his disappointment, taking the drug does not work and the dose is then increased in a series of increasingly desperate bids to obtain the effect. Reasons for the failure are again two-fold. On the one hand, if overgreedy and attempting to repeat the euphoria too frequently, inadequate time may be left for replenishment of body chemicals. On the other hand, the drug may be taken in a different setting, perhaps in isolation, and, lacking the group good fellowship may provoke a thoroughly unpleasant experience. As the dose is increased it is inevitable that other effects on the body occur which may be long-term or immediate. If some drugs are taken repeatedly for long periods of time body cells adapt physically to the presence of large amounts of the drug. When the drug is withdrawn this balance is upet and physical symptoms are again produced which only the drug can immediately subdue. The subject then takes the drug to quell undesirable symptoms rather than to gain positive pleasure. The undesirable immediate effects are those of a toxic delirium now to considered.

\section{(b) Drug delirium}

As addicts increase the dose to obtain euphoria a variety of other psychological symptoms occur which at first appear bewildering. However, exactly sixty years ago, in 1910, a German doctor, Bonhoeffer, pointed out that the brain although subject to an infinite variety of insults has only a limited number of ways in which it reacts. ${ }^{12}$ Any acute disturbance, i.e. one rapidly changing in time, produces a delirium (also referred to as acute brain syndrome, acute organic psychosis, acute toxic psychosis, or acute exogenous psychosis). The toxic delirium comprises (1) changes in consciousness-a complex business which approximates to changes in awareness of self and environment; (2) disturbances of perception.

Let me expand this description a little. In fully developed delirium there may be little awareness of environment and subjects pay no attention to events going on even when these are physically painful. Lesser impairment of consciousness (which is often termed "clouding") may be revealed by difficulty in grasping problems and giving answers. Subjects are frequently disorientated either in time or space or both and sometimes even uncertain on person. When the subject recovers, his memory is poor for the period under the influence of drug according to the degree of clouding. Fragments of memories may come back but frequently the individual has no recall of any of the events during this phase. It is possible to carry out really quite complicated actions and conversations under the influence of alcohol and yet have absolutely no memory of these subsequently.

As to the perceptual disturbances the mildest are impairment of normal perceptions; judgment of distance and depth may be distorted; or a small inkstain on a desk may be mistaken for a fly (an

12 Bonhoeffer, Symptomatischen Paychosen, (1910). 
illusion). In the full blown delirium grosser disturbances such as hallucinations occur. They can be distinguished from vivid mental imagery by the belief in reality. Patients have jumped out of windows to avoid what they are certain is a real bus bearing down on them and may even try to save your life by taking you with them. A recent patient of mine suffering late effects of LSD made serious attempts on her life convinced that snakes were crawling over her skin.

It would be a disservice both to you and the medical profession to give the impression that matters are quite so simple. This is indeed an area where the greatest medical and psychiatric expertise is required to avoid blunders and one must honestly admit that there are times when one cannot give a certain diagnosis. Nonetheless I believe that if you categorize the effects of drugs under the two headings of changes in awareness and changes in perception you will be able to account for the vast majority of phenomena described. In the smallest doses only a fragment of the picture may appear and the change in consciousness may not be in the direction of diminution but may increase alertness. This is true for amphetamine but most drugs diminish alertness and critical judgment diminishes too. The subject may be much more satisfied with himself but objective tests, e.g. of musicians after marijuana or drivers after alcohol show that there is considerable impairment in function.

Toxic delirium therefore is the prototype disturbance but this basic picture shows variations according to the chemical nature of the drug involved. Those addicted to opiates for example show as the most evident change a depression of consciousness reflected in inert behaviour and a dreamy state. On the other hand, the hallucinogens such as LSD cause marked perceptual disturbances and clouding of consciousness is less apparent although there when looked for.

We may summarize by saying that the acute effects of these drugs are initially euphoria and later the partial or complete production of a delirium with (1) changes in consciousness and (2) changes in perception. The degree to which a response such as this is elicited depends (a) partly on the drug itself (structure, dose, route of injection, etc.) (b) partly on the subject (physical constitution, psychological set) and (c) partly on the setting (convivial, isolated, etc.).

\section{CERTAINTY AND UNCERTAINTY IN MEDICAL DIAGNOSIS}

I emphasized earlier that the picture of delirium may be produced by a variety of agents besides drugs. A diabetic who has either taken too much insulin or missed a meal may have a low blood sugar and suffer precisely the same symptoms. Hence, the first step in dealing with a delirious subject is to find out as quickly as possible (either from the patient, relatives or any other available source) whether there is a previous history of illness or of drug taking. Many patients (such as diabetics) are instructed to carry cards around with them in their pockets declaring, e.g. that they suffer from " $X$ " and are taking "Y". Such information is then supplemented with a thorough physical examination of the patient as far as this may be possible when evidence of physical disease may be revealed or signs suspicious of addiction may emerge. Pinpricks in the elbow region of the left side (when the patient is right handed) may indicate selfinjection and addiction but even this can mislead. A diabetic or an 
asthmatic might be suspected quite erroneously of drug addiction on the same basis although the injection site is usually elswehere. Pinpoint pupils may suggest opiate addiction and dilated pupils and dark glasses LSD effects but equally these may be the result of cerebral hemorrhage or fear. Again a delirious man reeking of alcohol may be delirious from a concealed head injury. From all this you will appreciate that diagnosis in these cases is a matter where the utmost medical skill is called for. In itself the clinical diagnosis can no more incriminate drugs than cerebral hemorrhage or other organic diseases. There are, however, two ways of achieving greater certainty. Drugs IN the body. The first of these consists in finding the drug or its metabolites in the body fluids of the subject. If this is done, then I think it can surely be said that the delirium is at least in part caused by the drug. As I mentioned, such tests are available for all the common drugs of addiction with the exception of marijuana.

Drugs $O N$ the body. If drug metabolites or drugs are not found in the body fluids of the subject, however, then diagnosis must rest on circumstantial evidence and no one knows better than you the limitations of this. Such circumstantial evidence may include physical signs on the body of the addict such as multiple injection marks, dilated pupils and so forth, or sores around the mouth in the case of amphetamine addicts and may also include possession of drugs or equipment related thereto in the belongings of the subject.

\section{Marijuana}

In the case of marijuana the actual plant is an insignificant little shrub and is usually sold as dried leaves which have much the appearance of very coarse pipe tobacco. The leaves when rubbed up and inserted in an ordinary cigarette constitute a reefer or "joint." In this form it has been smuggled as the stuffing of rag dolls which seem an inevitable accompaniment of most young females at one stage of their development. A recent specimen obtained from the RCMP looked like khaki blanco. Marijuana when smoked in this fashion has a distinct odour which most people can spot and on occasion it has been useful to demonstrate this to nurses who have been able to diagnose on this basis alone. "Advances in dope pushing" have resulted in the much more potent resin (hashish) being extracted from the plant. This is a solid, brownish, black substance much like the ebony of which elephants sold as curios in the East are made. Such curio elephants have indeed been one means by which hashish has been smuggled into countries. Another is as the soles of shoes as hashish looks very much like brown leather.

\section{Heroin}

Heroin is much more potent and the quantities required are less and hence more easily concealed. The pure substance is white powder looking much the same to the inexpert as salt or sugar but it has a bitter taste (like other alkaloids). Ways in which it may be smuggled into hospitals and prisons are legion. One example is to mix it with talcum powder. This can be extremely difficult to detect; when the "talcum powder" has been safely smuggled in it is shaken up with water and a solution of heroin obtained and the talcum powder is left behind as an insoluble residue. Solutions themselves have also 
been smuggled in by soaking clothes, e.g. neckties, in strong heroin solutions and letting them dry. When a "fix" is required the tie is dipped in water or tea and the solution used for injection. One characteristic of the heroin addict is that the "fix" is invariably by injection so that a dirty syringe, often blood stained, puts one on one's guard. In addition, bent spoon with blackened bowl is suspicious as means of dissolving heroin in water by heat. Additionally, the marks of injection sites on the body of the patient can also be readily discerned. These do not invariably mean heroin addiction however because in recent years the amphetamine substances, particularly methedrine have been taken by this route and a variety of other weird substances have also been injected; peanut butter is the latest. Surprisingly despite poor antisepsis few come to harm through infection or blood poisoning.

\section{$L S D$}

LSD is even more potent than heroin and again comes usually as a solution which is taken as a drop or so on sugar, or. in capsules.

\section{DRUGS AND CRIME}

Drug addicts in the intervals when they are not under the influence of drugs are presumably as legally responsible for their actions as you and I. Yet it is particularly in this period that addicts will do almost anything in order to satisfy their craving. In the case of heroin it is also true that such addicts are suffering from a physical condition, the withdrawal syndrome. Does this then mitigate their responsibility? I would think not. Crimes committed under the influence of drugs form another category. I believe it is accepted in most courts of law that a man with a physical illness such as pneumonia who became delirious and murdered his wife would be in some part excused for his actions. Yet what of the taker of LSD who develops an entirely similar delirium and commits the same crime. Is he then partly excused as the pneumonia sufferer was? Again I think not because the drug taking was of the subject's own volition and hence he should be responsible for the consequences. In fact as most drugs depress activity, crimes in this state are relatively few., The exception is the amphetamine group which stimulates activity and aggression and which has undoubtedly been associated with a number of crimes of violence. Again the subject must presumably assume full responsibility. Perhaps in this connection I can exculpate marijuana from one alleged misdemeanor. It is well known that hashish and assassin are derived from the same root and it is commonly assumed that the hired killers murdered under the influence of the drug. Quite the reverse is true. They were given hashish as a reward for their actions (and presumably also to prevent them murdering others whilst between professional engagements).

\section{OUTCOME}

One of the undesirable effects of drugs is the loss of productive work from those who are potentially able to contribute much both to their own and society's welfare. The same can be said of alcohol and the morning absences after weekend drinking. It is, however, generally agreed that the "hard drugs" are the evil doers although amphetamines or "speed" given by injection are also regarded by the 
drug subculture as killers and they themselves advise against injecting these substances.

In the case of heroin the British Home Office index figures provide the only large factual data I know of an outcome and I summarize it herewith (Table 3).

Table 3

HEROIN INDEX ONLY OUTCOME

Of 1312 cases indexed 1954-1966

896 ( $68 \%$ ) continue

$416(32 \%)$ are concluded

$1312(100 \%)$

\section{Of 416 cases concluded}

187 ( $45 \%$ ) are cured

136 ( $33 \%)$ disappeared

93 ( $22 \%)$ died

$416(100 \%)$

Fig. 15

\section{CONCLUDED HEROIN CASES}

MORTALITY. DURATION AND ORIGIN

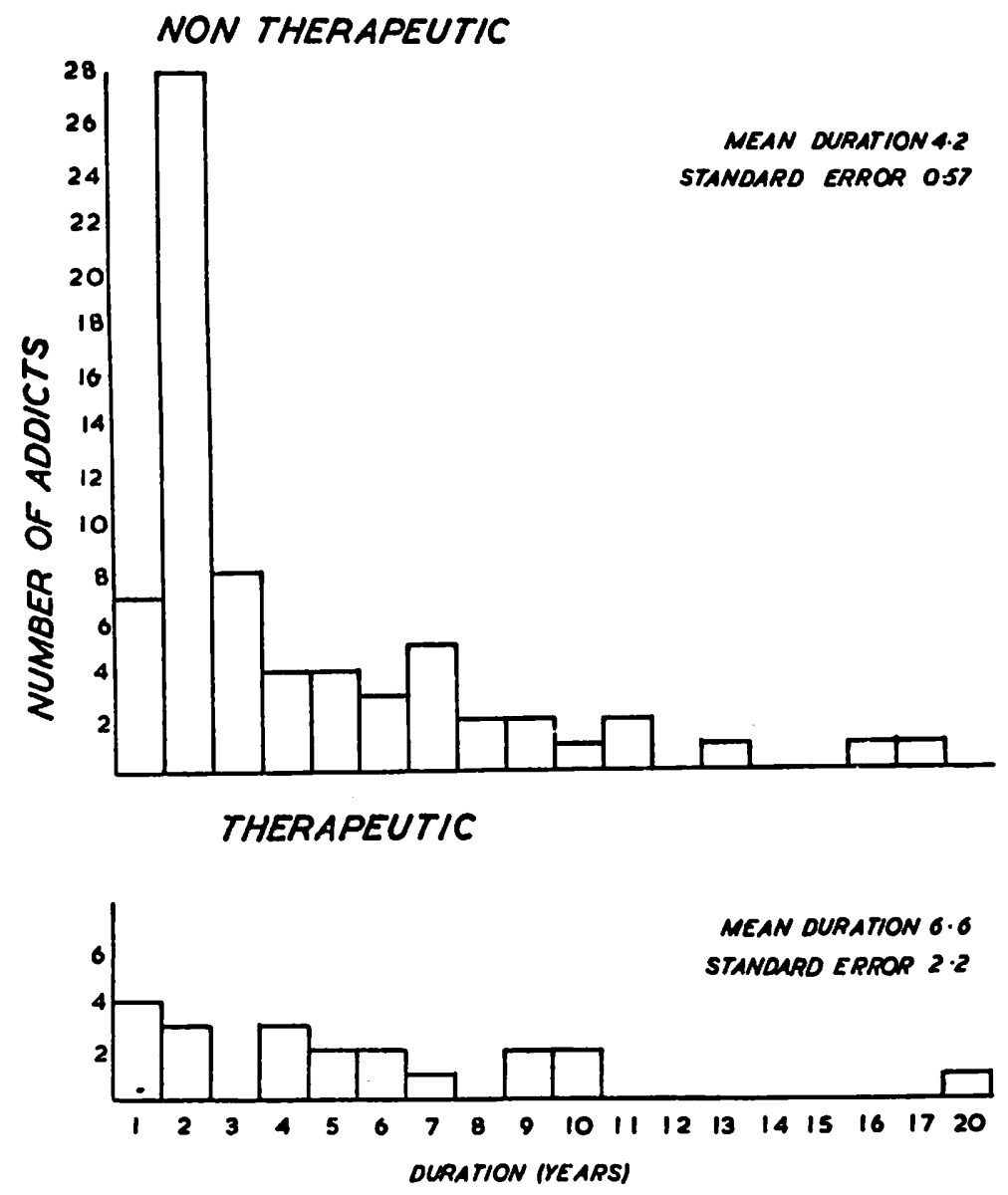


Of 416 cases concluded, $45 \%$ are cured, $22 \%$ died and $33 \%$ disappeared. A $22 \%$ mortality in a population of adolescents and young adults must surely be sufficient warning of the dangers of heroin. It is almost certain that this $22 \%$ is an underestimate for an unknown proportion of those who disappeared would also come into this category. So it appears that a minimum of $22 \%$ of the young adult population die and perhaps as many as $55 \%$ die. Looking more closely at this mortality (Fig. 15) it can be seen from the histogram that most die within two

Fig. 16

\section{CONCLUDED HEROIN CASES MORTALITY, AGE ANO ORIGIN}
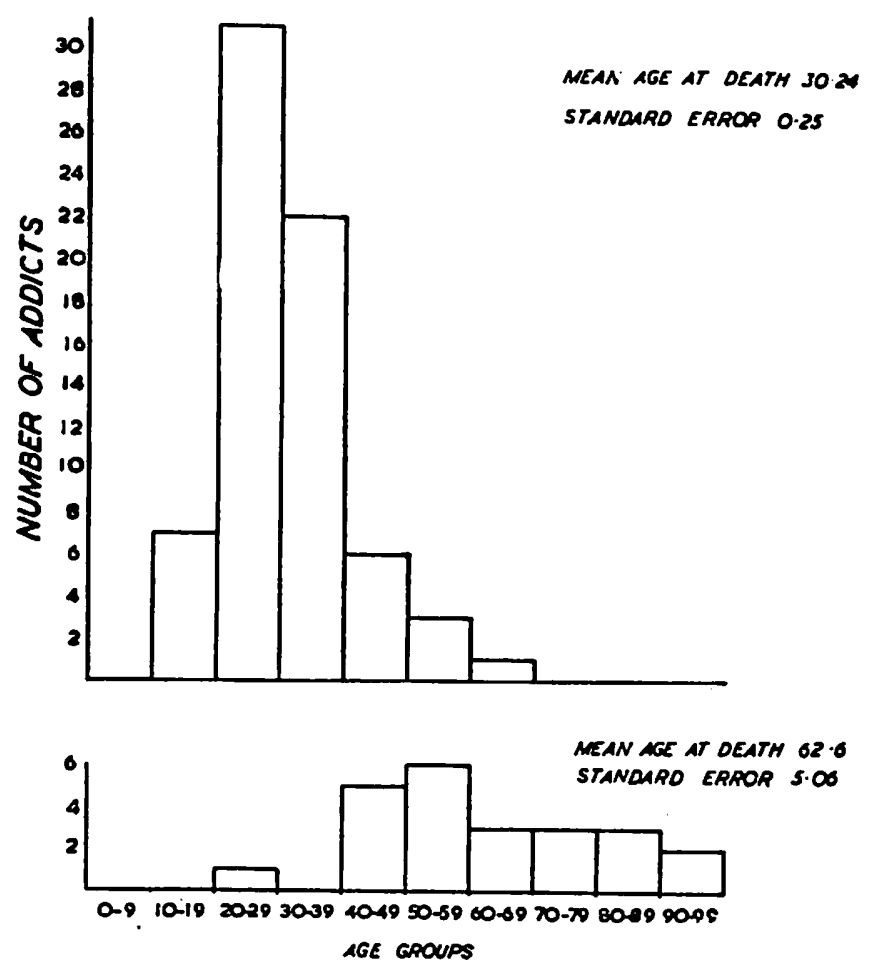

years of starting an addiction and the next histogram (Fig. 16) shows that the majority of deaths occur between twenty and twenty nine with a very sizable proportion occurring in thirty to thirty-nine age group and next in the ten to nineteen year old age group. Mortality of this sort in these age groups is horrifying.

What are the prospects for cure? The chances of cure are greatest in the first year of the addiction (Fig. 17) and thereafter tail off rapidly with each succeeding year of addiction. If the addiction has lasted three years or more the chances of cure though not impossible are certainly rather poor. As far as age is concerned apparently the 
younger you are, on the whole, the better the chances of cure (Fig. 18) and above thirty years recovery seems remote but the age incidence of addiction makes such conclusions unwarranted.

Although there are no LSD data comparable to that for heroin it can be stated unequivocally that it is associated with a very definite immediate mortality either due to direct toxic effects of the drug or indirectly through the induction of horrifying experiences which impel suicide or induction of beliefs that endanger life, e.g. that they can fly.

As to amphetamines, medical experience over long periods of

Fig. 17

\section{CONCLUDED HEROIN CASES}

CURE AND DURATION

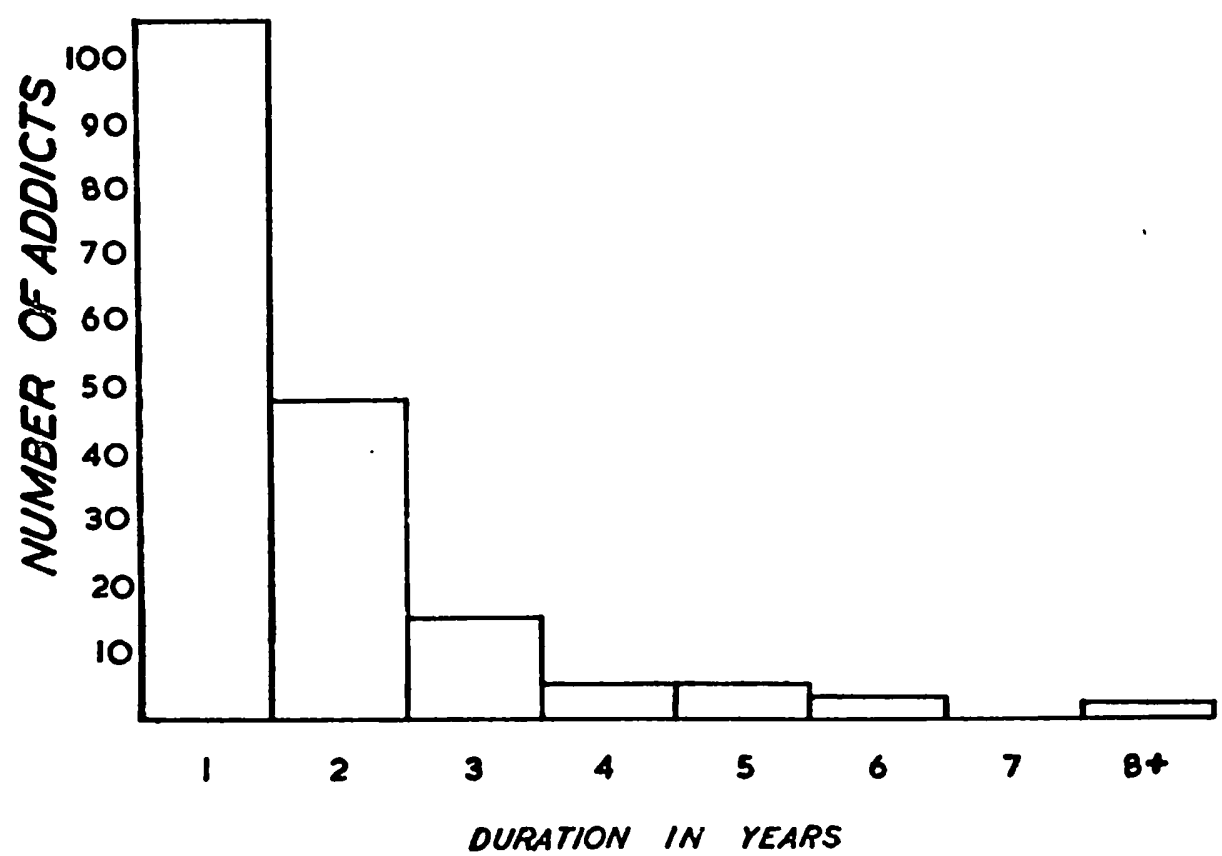

time with ordinary oral dosages indicates no serious hazards. There is no medical guide however on the habit of injecting methedrine in variable doses repetitively intravenously. Subjects have certainly died from acute hypertension and cerebral hemorrhage.

As to marijuana, no serious medical hazards seem to have been established yet but as with cigarettes accumulating data may well indicate some serious hazard to health. This we simply do not know and there is no one in the world today whatever his position who can say that no hazards exist. One should add that in common with all other drugs of addiction accidents can happen during the acute psychosis induced by the drug. Data on long term effects in countries 
where marijuana has long been in use might be looked for but I would suppose this to be a fruitless task as standards of medical care are low if they exist at all and the average expectation of life has only recently climbed above thirty years. The main charge levelled against marijuana by its critics is that it may lead to heroin addiction. That there is an association in western countries is undeniable but whether this association is causal or not is quite unproven, so that to say that marijuana causes heroin addiction is as inaccurate a statement as the one claiming no hazards at all. It is unfortunate but characteristic of this topic that it drives discussants into extreme and errone-

Fig. 18

\section{CONCLUDED HEROIN CASES}

\section{CURE AND AGE}

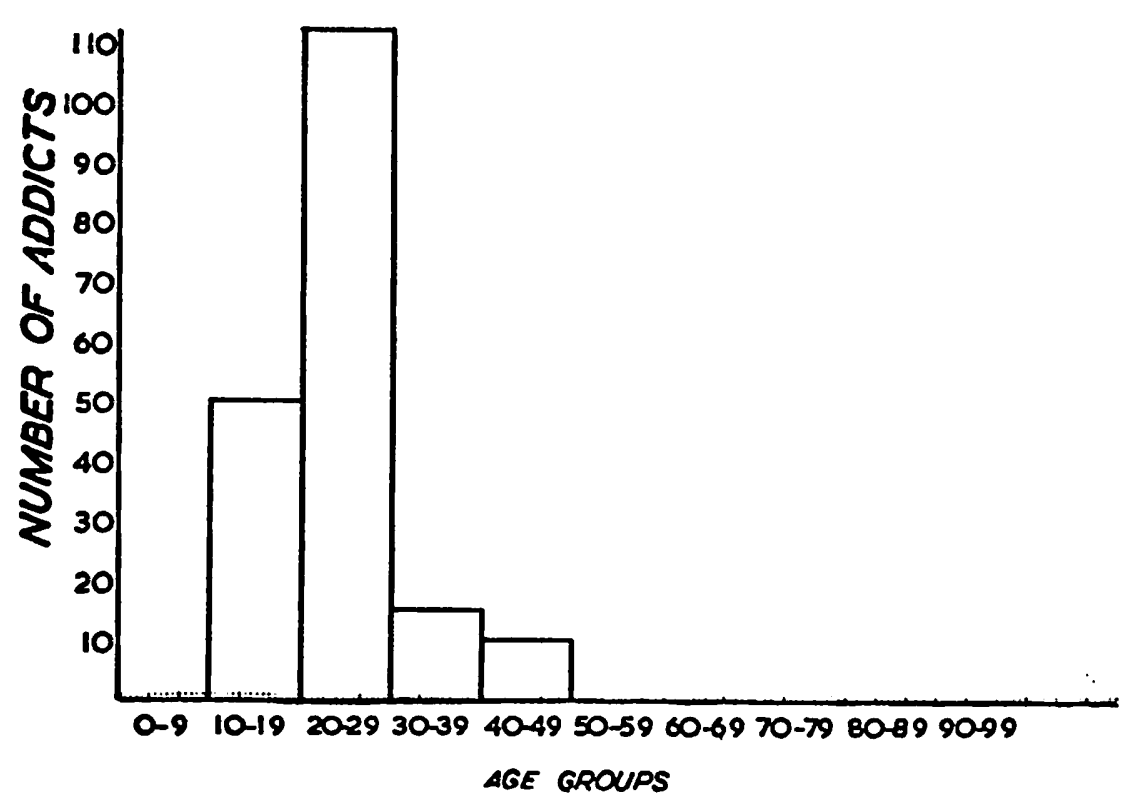

ous positions. The most likely but still speculative explanation is that marijuana and heroin are obtained from the same illicit source or illicit sources which at least are commonly found together. Those who wish to legalize marijuana would say that all heroin addicts have previously eaten and slept but it is also true to say (without in any way implying causal connections) that it is at least possible to avoid smoking marijuana whereas eating and sleeping cannot be sidestepped.

\section{TREATMENT}

Our offering in this area must be meagre despite the heroic efforts of a dedicated few and in spite of the laws which prescribe it. The toxic delirium can be dealt with satisfactorily but the underlying 
dependence proves an intractable problem in most cases. This is partly because the condition in some respects lies outside accepted notions of illness and may ultimately be dealt with better by social measures rather than medical ones. The concepts of health and disease with their many ramifications bearing on treatment, legal responsibility and other issues are topics of much wider extent and importance, indeed than drug addiction itself. Such matters deserve separate attention and they are not conveniently summarized here. At present one may simply say that the relapse rate is disappointingly high for most addictions and "cures"-less than 50\% as the Home Office figures show.

\section{PART 4-SUMMING UP AND CONCLUSIONS}

Let me now bring the threads of this discourse together. This requires care for the rope we fashion can either be a safety line or a means of hanging ourselves (or, being realistic, a means of hanging me).

\section{A. Similarities}

I have presented some of the evidence which shows that the mechanisms whereby dependency develops are similar whatever the drug. All addictive drugs are capable of producing euphoria (either directly or indirectly) but to produce such a state requires a normal brain chemistry and an appropriate psychosocial setting as well. As such factors are not always favourable drugs do not always produce the effect desired. The subject then mistakenly assumes that the dose was inadequate and increases it. Inevitably this produces other physical and psychological symptoms, the chief of the latter being a toxic psychosis. Additionally some drugs taken in large amounts over long periods of time force body cells to adapt to their presence; sudden withdrawal may then produce physical symptoms producing the so-called withdrawal syndrome (physical dependence) but this is not an essential criterion of dependency.

Recognition of the similarity in mechanisms between various drugs of addiction carries implications of which three deserve emphasis here.

1. Knowledge of alcoholism may be used as a temporary stopgap wherever present knowledge of drug addiction is deficient.

2. Those who drink or smoke are in no position to moralize on other addictions.

3. The widespread use of alcohol and tobacco indicates an equally widespread demand.

\section{B. Differences}

Whilst similarity is shown in the mechanisms by which dependence develops to addictive drugs, outcome differs widely. However, two main groupings are evident which I have called "quick-kill" and "slow-kill." In the "slow-kill" category are alcohol and cigarettes. It usually takes a lifetime of devotion to produce physical complications or social degradation from alcohol and hence the middleaged are plagued. The same is true for cigarettes and in both cases complications are not inevitable. The "quick-kill" category includes heroin, LSD and intravenous amphetamines. Heroin addiction is associated 
with a minimum mortality of $22 \%$ in an adolescent and young adult population and mostly occurs within two years of starting. Similar figures for LSD and intravenous amphetamines are lacking but both carry a definite and early mortality in an age group which should have none. No immediate fatalities have been recorded for marijuana but longterm effects need further evaluation and for the present I would therefore place it in the "slow-kill" category with a query against its name.

\section{Moral and Social Sequelae}

Whilst repercussions on the health of the individual are fairly well defined the effects on society are less easy to specify. They include the loss of useful contributions which drug-users might otherwise have made. Such losses may be temporary (although frequently recurrent) and sometimes permanent due to death. Such contributions may not have amounted to much in most cases, but occasionally the loss of a gifted talent seems a tragic waste. More intangible are the effects which entry into the drug subculture may have by spreading contempt for the law and rules of society. The involvement of school children in the practice brings moral aspects particularly to the fore although these underlie the whole problem.

\section{Aims}

Let us now clarify our aims for bad effects may be seen in moral, social, and medical terms. (a) Moral aspects are certainly important but at the present time difficult to specify in a form which would meet any general agreement. Smoking marijuana is immoral to some whereas the law against it is immoral to others. (b) Social effects are also difficult to categorize and often speculative. Social attitudes are equally diverse and always have been through the centuries: coffee was banned in Egypt in the 16th century; the Moslem has long accepted hashish whilst alcohol is held to be evil; "The wildest dreams of Kew are the facts of Khatmandhu and the crimes of Clapham chaste at Martaban." Today such differences are no longer separated by time or space and the paradox is clearly seen within the context of our own society. The wildest dreams of Kew are the facts of Kew and our current problem is whether those acts at Clapham are legally admissable or not. (c) In contrast, the medical aspects are much better defined and although our information is crude two categories of ill-effects are evident as matters of objective fact. This immediately gives two targets which are tangible and worthwhile. More important still, the avoidance or prevention of these ill-effects is one which unites drug-users and non-users in a wide measure of agreement. For drug-users the main benefit sought is the enlargement of experience, not its termination. Many in the drug subculture are aware of the dangers of intravenous amphetamines and campaign against them by wearing buttonholes with the slogan "Speed Kills." And they don't mean on the road. Recognition of the more horrifying mortality from heroin should also provoke a sensible reaction.

\section{E. Means-Undesirable}

How do we achieve these aims? In the case of heroin most countries have banned it completely and imposed the most severe penalties for breaches of the ban. Yet in the mid-1960's the United 
Nations Commission on Narcotics reported that the rate of heroin addiction per million population was 290 in the U.S., 180 in Canada and 20 in Britain where heroin was freely available by prescription of any doctor. Complete prohibition of heroin therefore is largely ineffective. This merely confirms previous experience with alcohol which although much less easily concealed was still widely distributed in the U.S. in the "dry" years between 1919 and 1933. The ineffectiveness of banning marijuana is equally evident. It is desperately important to recognize these unpleasant facts now. Adding more drugs to the banned list may satisfy the proprieties and provide paper comfort but as a practical and protective device it is so out of touch with reality that it is delusory and not only futile but dangerous. Instead we must ask why prohibition is such a failure and what alternatives exist.

Failure of prohibition has two aspects corresponding to the two causal categories of demand and supply. The demand is found in needs which the bulk of the population share. I know of no way whereby these human needs can be materially affected and even if such means were available their widespread application might well be disastrous. That a widespread demand exists is indeed given as the main reason for failure to enforce prohibitory laws. One has sympathy with the police in this situation but to blame it all on the consumer blatantly ignores the second aspect, namely the police failure to quell the source of supply. It is the little man, the consumer, and the last retailer in the chain, who pay the piper but they do not call the tune, for the mainstream of production continues unabated. The police have got no further than the peripheral twigs of what must be a very large tree or even forest of trees. Although 'a few leaves are shaken to the ground periodically and tidily put away in wire baskets by the Courts it seems that not even a main branch has been tackled or even sighted, let alone the trunk. Why this should be is a matter of crucial importance to which there are no satisfactory answers at present. We therefore have a situation based on general human needs together with a supply situation which caters for them in a most dangerous way and over which our society has no control. The gravity of this statement you must ponder on for yourselves.

\section{F. Means-Desirable}

If my analysis is correct the imperative aim must be to regain control and this transcends by far the importance of drug addiction per se. I think this can be done as follows.

Make the members of the "quick-kill" group all available by doctor's prescription and permit legal manufacture by reputable firms at minimum cost. The main change in the law would be to transfer the narcotics, notably heroin, to this category but not marijuana. No constraints whatever are to be imposed on doctors or their patients but those dealing with sources outside doctor's prescriptions must be dealt with severely.

I believe the following advantage would follow this course.

1. The supplier would be undercut and ultimately profit turn to

loss. He will no doubt diversify like all big businesses. 
2. Addicts will receive medical supervision when obtaining their prescription which at present is nonexistent.

3. The schoolchild in particular is cared for; their financial resources are obviously not worth the pushers efforts.

4. The addict is no longer forced to obtain further victims in order to receive supplies. This should radically alter the growth rate.

5. Crimes committed in order to obtain supplies, e.g. theft, etc. should fall and individual rehabiliation should further be helped as money previously spent on drugs can be used for better things.

6. An accurate gauge of the size of the problem may be kept by scrutiny of prescriptions and track kept of most addicts.

7. It would restore to the very sick a drug which has long been denied them. In terminal illnesses with intractible pain morphine and near allies, whilst effective pain killers, often make patients vomit or retch continuously. Such misery can be avoided by using heroin which has much less tendency to do this and is much more potent as an analgesic.

Let me clarify one thing. Making these drugs freely available by medical prescription is not an attempt to cut down supplies. The aim is to transfer the population of addicts to doctors. It has the social advantage that the problem is monitored and it is to the addict's advantage to receive cheap, pure heroin whilst supervision is given and (if wished) treatment. There must be no constraints on doctors or patients about these prescriptions. Otherwise doctors will be reluctant to prescribe and the whole aim will be defeated. I believe there need be no fear that the medical profession themselves will start an epidemic. We have the evidence of Britain where heroin has been freely available for many years without rises in heroin addiction. The recent rise is certainly due to extramedical causes and the numbers of therapeutic addicts has remained relatively stationary. It is true that individual doctors will vary in their attitudes to prescribing heroin. Some will find it against their conscience to do so at all and others will prescribe perhaps too freely. The majority, I am confident will cope with the matter sensibly as they have done in the past and deal with it as a-medical problem and not a moral one. Addicts will soon find doctors to their taste and prices to suit their pocket.

I should say a word about very recent changes in Britain which confine certain drugs of addiction to prescription only by special treatment centres. Central treatment centres for research are vital but confining prescription to these centres is I believe retrograde. It was done under the mistaken belief that over prescription by a few doctors caused the epidemic. This is nonsense. The success of the British experiment remains to be seen. One expects that many addicts will link treatment centres with withdrawal of the drug which is the last thing they want. This may in fact channel the addict to the underground market and play right into the suppliers' hands. We shall see.

What of the "slow-kill" category? This group I would treat along the lines of the present liquor laws in this province. I would also include tobacco or particularly cigarettes in the same category and make it mandatory. for such stores to display prominent notices stat- 
ing briefly and factually the dangers of the commodities supplied. If marijuana is to be legalized, then this surely is the category for it. Table 4 summarizes the main arguments for and against the legalization of marijuana. Items 1 to 5 on both sides indicate fairly even matching of arguments and lead to no conclusion. Much more important, I believe, are items 6 onwards. It is claimed that legalization of marijuana would not be carried out because of possible association with heroin addiction. I do not regard marijuana as being causal in any physiological or pharmacological sense in heroin addiction but I have no doubt this is so through social contiguity when marijuana is obtained from illicit sources of the kind which also pro-

Table 4

\section{Arguments for and against legalization of marijuana}

\section{FOR LEGALIZATION}

1. Would provide better alternative to alcohol or tobacco.

2. It has been added already whether we like it or not.

3. Illogical in biological terms to treat it differently to alcohol.

4. As most use alcohol and/or tobacco hypocritical not to accept marijuana.

5. Hypocritical of government to retail alcohol but to prosecute retailers of other intoxicants.

6. Deprive pusher of profit.

7. Removes it from social contiguity with heroin.

8. Would minimize supply to school children if control as effective as alcohol.

9. Would deny it to school leavers as a symbol of rebellion.

10. Destroys mystique of "sacrament" and places it at "getting drunk" level.

11. Source of revenue.

12. Brings it into the open and under control and can be discussed with parents freely and with others.

\section{AGANST LEGALIZATION}

1. Would add one more problem to those we have already in alcohol and tobacco.

2. Adverse immediate sequelae and unknown longterm complications.

3. Relation to heroin addiction.

4. Two wrongs do not make a right.

5. Gives official sanction to a bad habit.

duce heroin. Indeed I think this is the strongest argument for legalization of marijuana. If the liquor laws were applied to marijuana as well and as effectively as alcohol then the incidence of marijuana smoking in schoolchildren should be drastically reduced. If the age acceptable for purchase of alcohol and marijuana were reduced to eighteen this would also deny the youth leaving school the luxury of defying ?.thority by smoking it. But over and above everything else it is essential in my view to regain control of a drug situation which is out of our hands. We must do this speedily otherwise we shall not have a society worth talking about.

If all these measures are carried out $I$ believe that we will regain control whilst bringing medical aid to the place where it is sorely needed and cut time wasting of Courts and Police. It further does justice to the biology of the situation which is much more comfortable 
and at the same time increases revenues to the state instead of spending them. I must emphasize that I do not present these solutions dogmatically. They simply seem to me to be the best and most sensible ways out of our dilemma. This of course is open to debate and if you have better solutions or insuperable objections then let us discuss them now but as matters of reason, not emotion. The situation to my mind is too serious for anything else. It is also essential to say that solutions must be practical. It is no good assuming an ideal human being or a Utopia which is not with us. We all take our pleasure in different ways and some relaxation is essential for most of us. Asceticism may be noble but it is certainly atypical. "Chastity," said Oscar Wilde, "is the most unnatural of perversions." And on this he spoke as an expert. It must be left to the good sense of the individual to judge whether his periods of relaxation are in due proportion to periods of productiveness and for his own social group to judge him if not.

I hope it is clear that on this topic I speak only for myself. I am not associated in any way with official bodies dealing with the matter, and this perhaps has advantages for in such situations one is tied by loyalty. Thus the police have to defend enforcement. A report placed before Edmonton City Council on Monday, April 27, 1970, prepared by the City Police Department stated, ${ }^{13}$ "While enforcement is not a complete and total answer to the drug problem, it surely reduces the incidence of offences and contains the present problem at tolerable levels." The same report quoted 37 arrests or summonses on drug charges were made in 1967, 248 in 1968, and 387 in 1969. "The early trend for 1970 clearly indicates no abatement in the arrest rate and a healthy statistical report of arrests is now projected for this present year." This may be healthy for the Police Department but not for anyone else, nor would many agree that matters are being contained at tolerable levels. The report complains about existing drug laws and hopes for enlightened legislation. However, it does not favour legalization of marijuana and, as usual, states, "The individual must be the basis of the solution." Doctors and lawyers equally have their own distinctive point of view.

It is perhaps a sign of hope in Canada that the Law Reform Commission is now fact and of its four tasks the development of new approaches to changing needs is regarded as the most important. If the Minister of Justice, John Turner, has his way and the Commission is composed of "reform-minded tigers"14 they can find no better topic than this to start with.

\section{Acknowledgements}

I am grateful to the Dangerous Drugs Section of the Home Office of Great Britain who supplied most of the British statistics as well as background information. The Dominion Bureau of Statistics provided Canadian figures and I am grateful to Mr. Robert McKim and my wife for their help in locating and graphing this data. Finally, I thank my secretary, Mrs. Austin, for the trouble and care she took in making undecipherable manuscript into impeccable typescript.

\footnotetext{
13 Edmonton Journal, April 29, 1970.

14 Id., April 24, 1970.
} 